\title{
Sensitivity of Southern Ocean overturning to wind stress changes: Role of surface restoring time scales
}

\author{
Xiaoming Zhai ${ }^{\mathrm{a}, *}$, David R. Munday ${ }^{\mathrm{b}}$ \\ ${ }^{a}$ Centre for Ocean and Atmospheric Sciences, School of Environmental Sciences, \\ University of East Anglia, Norwich, UK \\ ${ }^{b}$ Atmospheric, Oceanic and Planetary Physics, Department of Physics, University of \\ Oxford, Oxford, UK
}

\begin{abstract}
The influence of different surface restoring time scales on the response of the Southern Ocean overturning circulation to wind stress changes is investigated using an idealised channel model. Regardless of the restoring time scales chosen, the eddy-induced meridional overturning circulation (MOC) is found to compensate for changes of the direct wind-driven Eulerian-mean MOC, rendering the residual MOC less sensitive to wind stress changes. However, the extent of this compensation depends strongly on the restoring time scale: residual MOC sensitivity increases with decreasing restoring time scale. Strong surface restoring is shown to limit the ability of the eddyinduced MOC to change in response to wind stress changes and as such suppresses the eddy compensation effect. These model results are consistent with qualitative arguments derived from residual-mean theory and may have important implications for interpreting past and future observations.
\end{abstract}

Keywords: Surface restoring, Southern Ocean, Ocean eddies, Meridional

\footnotetext{
${ }^{*}$ Corresponding author

Email address: xiaoming.zhai@uea.ac.uk (Xiaoming Zhai)
} 
overturning circulation, Eddy compensation, Wind forcing, Ocean modelling

1

2

\section{Introduction}

Upwelling in the Southern Ocean, driven by the prevailing westerly winds, plays a key role in closing the Meridional Overturning Circulation (MOC) of the global ocean (e.g. Marshall and Speer, 2012). Changes of the strength of this upwelling branch of the MOC associated with changes of the Southern Ocean winds have been proposed as an important mechanism for regulating global climate, in particular, through enhancing or reducing the communication between the carbon-rich deep ocean and the surface (e.g. Toggweiler and Russell, 2008; Anderson et al., 2009). Projections from state-of-theart climate models suggest that the Southern Ocean westerlies are likely to strengthen as well as become stormier over the next few decades (e.g. Solomon et al., 2007; Chang et al., 2012), both of which act to enhance the Southern Ocean surface wind stress (e.g. Zhai et al., 2012; Zhai, 2013). However, the robust response of the Southern Ocean overturning circulation to changes of the wind field is yet to be determined.

The problem of how the Southern Ocean responds to changes in surface wind stress has been investigated previously in both ocean-only and coupled general circulation models (e.g. Fyfe and Saenko, 2006; Hallberg and Gnanadesikan, 2006; Meredith and Hogg, 2006; Farneti et al., 2010; Viebahn and Eden, 2010; Abernathey et al., 2011; Meredith et al., 2012; Munday et al., 2013). Models that resolve mesoscale ocean eddies are generally found to be less sensitive to wind stress changes than those with parameterised ed- 
dies in terms of both circumpolar volume transport/global pycnocline depth and MOC. This insensitivity comes from the subtle balance between the wind-driven Eulerian-mean MOC that acts to steepen isopycnals and the eddy-induced MOC that acts to flatten them out; this balance largely determines the net residual MOC in the Southern Ocean (e.g. Marshall, 1997). Note that it is the residual circulation that advects temperature, salinity, $\mathrm{CO}_{2}$ and other climatically-important tracers in the eddying ocean.

In eddy-resolving ocean models, an increase in the Southern Ocean wind stress results in enhanced Ekman divergence and convergence that acts to tilt the isopycnals further and increase the mean available potential energy (APE) of the system. This leads to the generation of a more vigorous eddy field that releases the newly-increased APE and at least partially compensates for changes of the wind-driven overturning. As a result, the residual MOC is rendered less sensitive to changes of wind stress, that is, changes of the residual MOC are much smaller than those of the direct winddriven Eulerian-mean MOC (the so-called eddy compensation effect; Viebahn and Eden (2010)). It is, however, unlikely to have perfect eddy compensation due to the different depth dependence of the Ekman and eddy-induced transports; changes of the Ekman transport are strongly surface-intensified whereas changes of the eddy-induced transport spread over the whole water depth (e.g. Morrison and Hogg, 2013).

The extent to which changes in the eddy-induced MOC compensate for changes in the wind-driven Eulerian-mean MOC varies among different eddyresolving models. For example, relatively weak sensitivity of the residual MOC to altered wind forcing is found in an eddying model of Hallberg 
and Gnanadesikan (2006), while greater sensitivity is found in the models of Viebahn and Eden (2010) and Munday et al. (2013). Recently, Abernathey et al. (2011) showed that the sensitivity of the Southern Ocean residual MOC to changes of the wind forcing depends on the surface boundary condition for buoyancy: a fixed surface buoyancy flux boundary condition severely limits the ability of the residual MOC to change, whereas the use of a Haney-type restoring boundary condition for buoyancy (Haney, 1971) leads to greater sensitivity. Since in thermodynamic equilibrium the residual MOC matches the buoyancy forcing (e.g. Walin, 1982; Watson and Naveira Garabato, 2006; Badin and Williams, 2010), the higher degree of freedom at which surface buoyancy flux can vary under the restoring boundary condition implies a higher sensitivity of the residual MOC.

In Abernathey et al. (2011), a surface restoring time scale of 30 days was used for model experiments under the restoring boundary condition. In the ocean, due to the lack of observations, it remains unclear on what time scales the surface turbulent heat fluxes damp the sea surface temperature anomalies, although the spatial scales of these anomalies are believed to be important (e.g. Bretherton, 1982; Frankignoul, 1985)ํ․ For example, studies based on heat flux data derived from ship and satellite observations suggest that the restoring time scales can vary from less than one month to almost one year in the Southern Ocean, depending on season and location (e.g. Park et al., 2005). Recently, Shuckburgh et al. (2011) studied the mixed layer lat-

\footnotetext{
${ }^{1}$ The situation for the sea surface salinity (SSS) is very different because it does not rain preferentially over regions of positive SSS anomalies nor evaporate preferentially over regions of negative SSS anomalies (e.g. Zhai and Greatbatch, 2006a,b)
} 
a

eral eddy fluxes mediated by air-sea interaction and found a large sensitivity of surface eddy diffusivity to prescribed surface restoring time scale. However, the question of whether and how the sensitivity of the Southern Ocean MOC to changes in wind stress depends on the surface restoring time scale is, to our knowledge, yet to be explored.

The aim of this study is to investigate the effect of different surface restoring time scales on the response of the Southern Ocean overturning to wind stress changes, extending the recent work by Abernathey et al. (2011). We begin in Section 2 by presenting some qualitative arguments based on the residual-mean framework of Marshall and Radko (2003) to illustrate the influence of different surface boundary conditions. After describing the numerical model setup and experiment design in Section 3, we present and discuss changes of the eddy-induced and residual MOCs in response to wind stress changes in experiments with various restoring time scales in Section 4. We close with a summary in Section 5.

\section{Role of surface restoring on Southern Ocean response} to illustrate the influence of different surface restoring time scales on the response of the Southern Ocean to wind stress changes. The time and zonallyaveraged buoyancy equation is given by

$$
J\left(\Psi_{r e s}, \bar{b}\right)=\frac{\partial \bar{B}}{\partial z},
$$

where $b=-g\left(\rho-\rho_{0}\right) / \rho_{0}$ is buoyancy, $B$ is the buoyancy forcing, $\Psi_{\text {res }}$ is the streamfunction of the residual circulation in the meridional plane (MOC), 
and the eddy-induced MOC is given by

$$
\Psi^{*} \simeq-L_{e}^{2} N s^{2}
$$
diffusivity.

$$
K \simeq V_{e} L_{e}
$$
(see Fig. 1), the eddy diffusivity is then given by

$$
K \simeq-L_{e}^{2} N s
$$

where $\tau$ is zonal wind stress, $\rho_{0}$ is reference density, $f$ is the Coriolis parameter, $s=-\bar{b}_{y} / \bar{b}_{z}$ is the mean isopycnal slope and $K$ is the eddy thickness

Using mixing length theory, the eddy diffusivity can be expressed as

where $V_{e}$ denotes a characteristic eddy velocity and $L_{e}$ denotes a characteristic eddy length scale. Following Visbeck et al. (1997) and Marshall et al. (2012), we assume that $V_{e} \simeq \sigma L_{e}$, where $\sigma$ is the Eady growth rate, given by

$$
\sigma=\frac{f}{\sqrt{R i}}=\frac{f}{N /\left|\bar{u}_{z}\right|}=N|s| .
$$

Here $N$ is the buoyancy frequency with $N^{2}=\bar{b}_{z}$. Eq. (4) shows that the eddy growth rate depends linearly on the mean isopycnal slope. Combining Eqs. (2), (3) and (4), while noting that $s$ is always negative in our model 


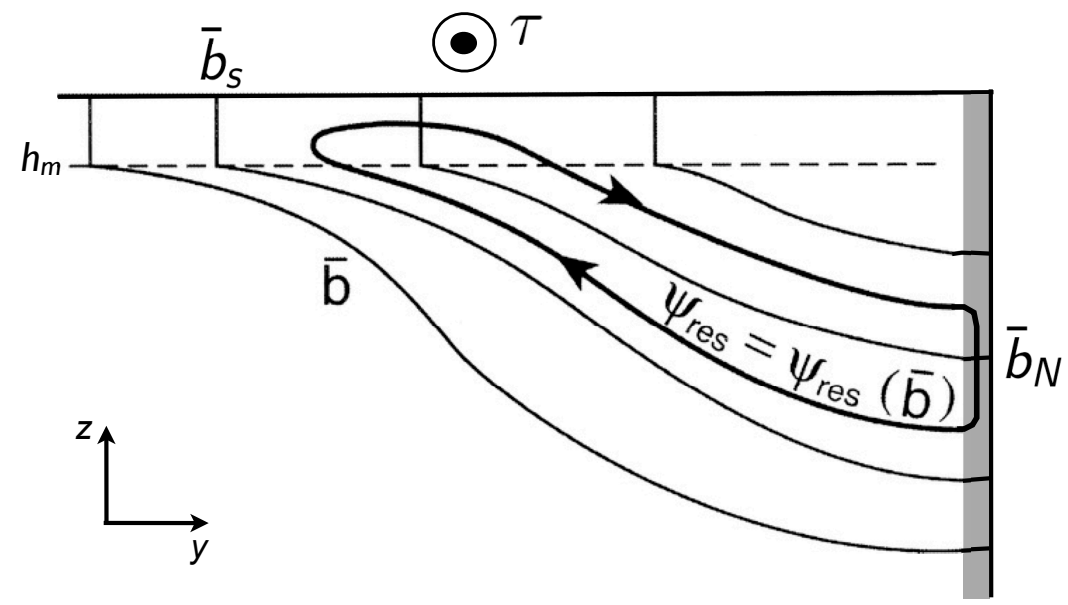

Figure 1: Schematic of the conceptual model (modified from Marshall and Radko (2003)). The residual MOC is directed along the mean isopycnals in the ocean interior and closed by diapycnal circulation in the surface diabatic and northern sponge layers. The northern sponge layer is shaded in grey.

The eddy-induced MOC is therefore anticlockwise and depends quadratically on the mean isopycnal slope (e.g. Visbeck et al., 1997).

Following Marshall and Radko (2003), we assume zero stratification within the surface mixed layer and neglect the entrainment fluxes at its base. Integrating Eq. (1) over the depth of the surface mixed layer $h_{m}$ while noting $\Psi_{\text {res }}=0$ at the surface gives

$$
\Psi_{\left.r e s\right|_{z=-h_{m}}} \frac{\partial \bar{b}_{s}}{\partial y}=\bar{B}
$$

where $\bar{B}$ is interpreted as the effective buoyancy forcing that includes both air-sea buoyancy fluxes and lateral diabatic eddy fluxes in the mixed layer.

In the ocean interior, we assume the buoyancy forcing is weak, i.e., $B=0$, and Eq. (1) reduces to

$$
J\left(\Psi_{r e s}, \bar{b}\right)=0
$$


meaning that the residual circulation remains constant along the mean isopycnals, i.e., $\Psi_{\text {res }}=\Psi_{\text {res }}(\bar{b})$.

At the northern boundary of our model, the buoyancy distribution throughout the water column is prescribed through a restoring boundary condition at a short time scale, i.e.,

$$
\bar{b}=\bar{b}_{N}(z)
$$

Physically, $\bar{b}_{N}$ is set by ocean adjustment to global diabatic processes further to the north of our model domain (Munday et al., 2011). Figure 1 shows a schematic of the conceptual model used by this study. We now consider surface restoring boundary conditions at two limits.

\subsection{Strong surface restoring}

In the limit of strong surface restoring $\left(\lambda \gg \sigma\right.$, where $\lambda^{-1}$ is the surface restoring time scale), buoyancy at the surface, $b_{s}$, is effectively prescribed, leaving the isopycnal slopes little freedom to vary. Since the eddy-induced MOC is, to a large extent, determined by the isopycnal slopes (see Eq. (6)), changes of the eddy-induced MOC, and therefore the ability of eddies to compensate for wind stress changes, is severely suppressed. As a result, the residual MOC exhibits a large sensitivity to changes of the wind forcing, with changes of the residual MOC, $\Delta \Psi_{\text {res }}$, approaching that of the Eulerian-mean MOC, $\Delta \bar{\Psi}$, i.e.,

$$
\Delta \Psi_{\text {res }} \sim \Delta \bar{\Psi}=-\frac{\Delta \tau}{\rho_{0} f} .
$$

Changes in the effective buoyancy forcing associated with changes in wind stress can be approximated by

$$
\Delta \bar{B} \sim-\frac{\Delta \tau}{\rho_{0} f} \frac{\partial \bar{b}_{s}}{\partial y} .
$$


155

Physically, in the strong surface restoring limit, stronger surface Ekman flow driven by increased wind stress crosses the mean isopycnals in the mixed layer experiencing swift water mass transformation due to the efficient surface restoring buoyancy flux. As a result, the isopycnals do not alter their mean slope. This is the diabatic surface Ekman drift situation.

The mean APE of the ocean is proportional to the mean isopycnal slope squared (Smith, 2007). It follows that the surface restoring boundary condition acts as a source of mean APE by preventing the isopycnals from slumping when the wind stress weakens. However, it acts as a sink for the mean APE by preventing the isopycnals from further steepening when the wind stress strengthens. This is particularly clear in the case of our numerical experiments without surface wind stress forcing (see Section 4).

\subsection{Weak surface restoring}

In the limit of weak or no surface restoring ( $\lambda \ll \sigma$; no restoring, i.e., $\lambda^{-1}=$ infinity, corresponds to a fixed surface buoyancy flux), $b_{s}$ at the surface is free to change, while being related to $b_{N}$ at the model northern boundary via the isopycnal slope $s$,

$$
\bar{b}_{s}(y)=\bar{b}_{N}(z=-y s)
$$

with

$$
\frac{\partial \bar{b}_{s}}{\partial y}=-s \frac{\partial \bar{b}_{N}}{\partial z}
$$

if we assume $s$ is uniform. Eq. (7) can now be rewritten as

$$
\left(\frac{\tau}{\rho_{0} f} s-K s^{2}\right) \frac{\partial \bar{b}_{N}}{\partial z}=\bar{B}
$$


which can be solved either analytically or numerically for $s$ for given $\tau, \bar{b}_{N}$ and $\bar{B}$. Note that $\bar{B}$ includes not only air-sea buoyancy fluxes but also lateral diabatic eddy transfer in the mixed layer. Although air-sea buoyancy fluxes are more or less fixed in the weak surface restoring limit, the diabatic eddy fluxes in the mixed layer may still change in response to changes of wind stress. If we assume the overall changes of $\bar{B}$ are small in the weak surface restoring limit (see also Abernathey et al., 2011), it then follows from Eq. (14) that the isopycnal slope $s$ (and hence the eddy-induced MOC) must change in response to changes in wind stress. Stronger Ekman flow advects the mean isopycnals in the mixed layer and tilts the isopycnals further, leading to a stronger eddy field that acts to shift the mean isopycnals back.

Assuming that the isopycnal slope increases from $s$ to $s+\Delta s$ in response to wind stress changes from $\tau$ to $\tau+\Delta \tau$, the eddy diffusivity then increases from $K$ to $K+\Delta K$ with $\Delta K=-L_{e}^{2} N \Delta s$. Substituting these into Eq. (14) and neglecting higher order $\Delta s$ terms, we obtain

$$
\Delta s=\frac{-\frac{\Delta \tau}{\rho_{0} f}}{3 L_{e}^{2} N s^{2}+\frac{\tau}{\rho_{0} f}} s .
$$

Changes of the residual circulation $\Psi_{\text {res }}$ is given by

$$
\Delta \Psi_{r e s}=-\frac{\Delta \tau}{\rho_{0} f}+K \Delta s+s \Delta K
$$

where the quadratic $\Delta s \Delta K$ term has been dropped. After some simple algebra, we find

$$
\Delta \Psi_{\text {res }}=-\frac{\Delta \tau}{\rho_{0} f} \frac{L_{e}^{2} N s^{2}+\frac{\tau}{\rho_{0} f}}{3 L_{e}^{2} N s^{2}+\frac{\tau}{\rho_{0} f}} \approx-\frac{\Delta \tau}{\rho_{0} f}\left(\frac{\Psi_{r e s}}{2 \Psi^{*}}\right) .
$$

The key point here is that although $\Delta \Psi_{\text {res }}$ still scales linearly with changes of wind stress, the slope is much reduced in comparison with Eq. (10) since 
177

$\left|\Psi_{\text {res }}\right| \ll\left|2 \Psi^{*}\right|^{2}$. This result means that the residual circulation is much less sensitive to wind stress changes in the weak surface restoring limit than in the strong surface restoring limit.

\section{Numerical model experiment}

We now examine the effect of different surface restoring time scales on the response of the Southern Ocean to wind stress changes using an idealised Southern Ocean channel model setup similar to Abernathey et al. (2011).

The model used in this study is the MIT general circulation model (MITgcm; Marshall et al. (1997)). The model domain is a zonally re-entrant channel that is $1000 \mathrm{~km}$ in zonal extent, $2000 \mathrm{~km}$ in meridional extent, and $2985 \mathrm{~m}$ deep with a flat bottom. There are 33 geopotential levels whose thickness increases with depth, ranging from $10 \mathrm{~m}$ at the surface to $250 \mathrm{~m}$ at the bottom. The horizontal grid spacing is chosen to be $10 \mathrm{~km}$ that is sufficiently fine to permit a vigorous eddy field but not so computational expensive that a large number of sensitivity experiments can be conducted. Additional model runs at a finer resolution (i.e., $5 \mathrm{~km}$ ) reveal only small quantitative differences. The model uses a linear equation of state and has no salinity such that the model density depends only on temperature. We

\footnotetext{
${ }^{2}$ In this simple model, changes of $\Psi^{*}$ tend to over-compensate for changes of $\bar{\Psi}$, which may be related to a number of simplifications invoked here such as uniform $s$ and invariant $\bar{B}$. If changes in $\bar{B}$ are taken into account, $\Delta \Psi_{r e s} \approx-\frac{\Delta \tau}{\rho_{0} f}\left(\frac{\Psi_{r e s}}{2 \Psi^{*}}\right)-\frac{1}{s} \frac{\Delta \bar{B}}{\partial \bar{b}_{N} / \partial z}$, where $\Delta \bar{B}$ can be further related to changes in $K$ and $\partial \bar{b}_{s} / \partial y$. Here we do not intend to provide a comprehensive quantitative solution to this problem, but simply use the qualitative arguments derived here to help interpret results obtained from our numerical experiments.
} 
Table 1: Key physical and numerical parameters used in the model experiments.

\begin{tabular}{|c|c|c|}
\hline Symbol & Value & Description \\
\hline$L_{x}, L_{y}$ & $1000 \mathrm{~km}, 2000 \mathrm{~km}$ & Domain size \\
\hline$H$ & $2985 \mathrm{~m}$ & Domain depth \\
\hline$\Delta x, \Delta y$ & $10 \mathrm{~km}$ & Horizontal grid spacing \\
\hline$\Delta z$ & 10 to $250 \mathrm{~m}$ & Vertical grid spacing \\
\hline$\tau_{0}$ & $0,0.1,0.2,0.3 \mathrm{~N} \mathrm{~m}^{-2}$ & Wind stress magnitude \\
\hline$Q_{0}$ & $10 \mathrm{~W} \mathrm{~m}^{-2}$ & Surface heat flux magnitude \\
\hline$\lambda^{-1}$ & 1 day to infinity & Surface restoring time scale \\
\hline$\lambda_{\text {sponge }}^{-1}$ & 7 days & Sponge-layer relaxation time scale \\
\hline$r_{b}$ & $1.1 \times 10^{-3}$ & Linear bottom drag coefficient \\
\hline$\kappa_{v}$ & $1 \times 10^{-5} \mathrm{~m}^{2} \mathrm{~s}^{-1}$ & Vertical diffusivity \\
\hline$\kappa_{h}$ & 0 & Horizontal diffusivity \\
\hline$A_{v}$ & $1 \times 10^{-3} \mathrm{~m}^{2} \mathrm{~s}^{-1}$ & Vertical viscosity \\
\hline$A_{4}$ & $1 \times 10^{10} \mathrm{~m}^{4} \mathrm{~s}^{-1}$ & Horizontal biharmonic viscosity \\
\hline
\end{tabular}

employ the K-profile parameterization (KPP) vertical mixing scheme (Large et al., 1994) and a linear bottom friction with drag coefficient of $1.1 \times 10^{-3}$. Table 1 lists the key physical and numerical parameters used in our model experiments.

The model is forced by zonal wind stress and heat fluxes at the surface and restored to a prescribed stratification profile, $T_{N}(z)$, in a sponge layer along the northern boundary on a short time scale of 7 days (Fig. 2). The surface heat flux and zonal wind stress take the same form as in Abernathey 

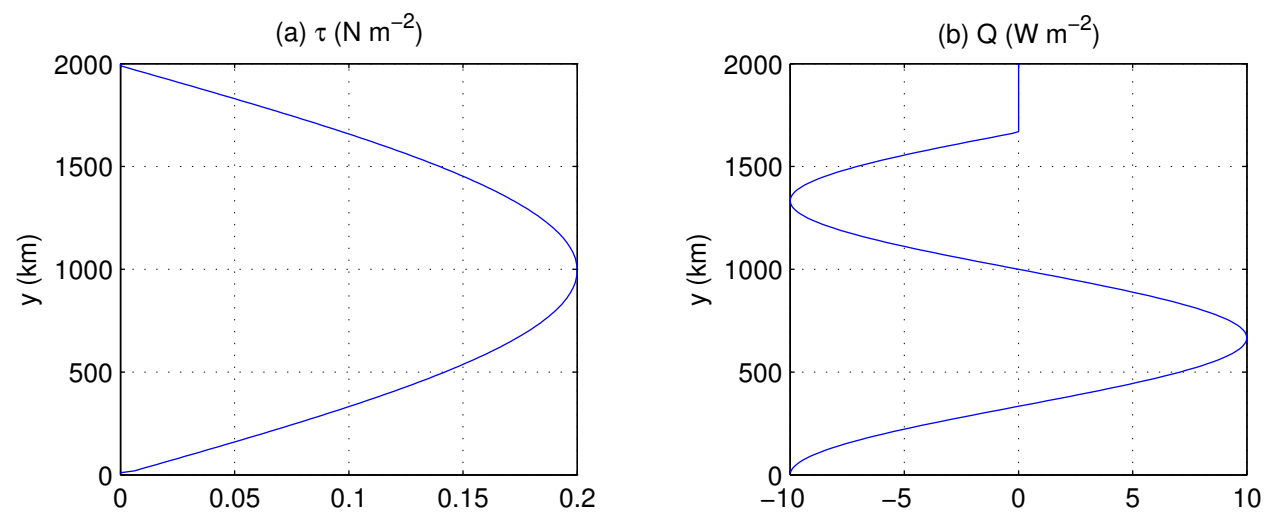

(c) $\mathrm{T}_{\mathrm{N}}\left({ }^{\circ} \mathrm{C}\right)$

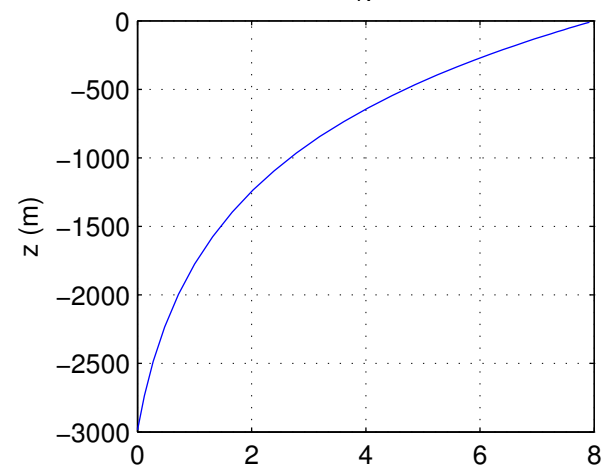

(d) $\mathrm{T}_{\text {ref }}\left({ }^{\circ} \mathrm{C}\right)$

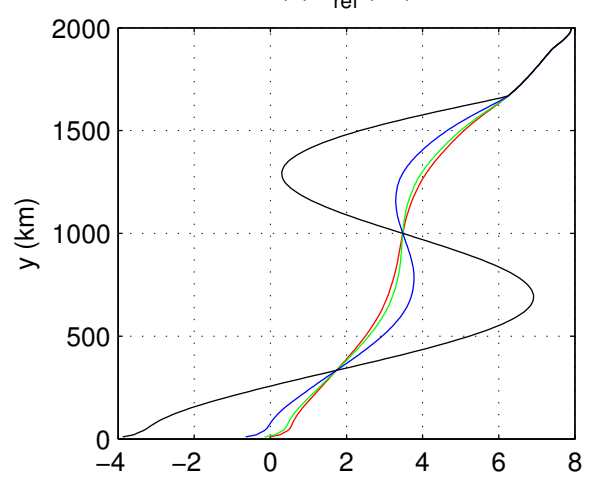

Figure 2: a) The surface wind stress $\tau$, (b) surface heat flux $Q$, and (c) restoring temperature profile at the northern boundary used in the first 800-year spinup, and (d) the reference temperatures used for the second 300-year spinup. The red, green, blue and black lines in (d) are $T_{\text {ref }}$ for model experiments with $\lambda^{-1}=1$ day, 1 week, 1 month, and half a year, respectively. 
et al. (2011):

$$
Q(y)= \begin{cases}-Q_{0} \cos \left(3 \pi y / L_{y}\right) & \text { for } y<5 L_{y} / 6 \\ 0 & \text { for } y>5 L_{y} / 6\end{cases}
$$

and

$$
\tau(y)=\tau_{0} \sin \left(\pi y / L_{y}\right),
$$

where $L_{y}=2000 \mathrm{~km}$ is the meridional width of the domain. During the first stage of model spinup, $Q_{0}=10 \mathrm{~W} \mathrm{~m}^{-2}$ and $\tau_{0}=0.2 \mathrm{~N} \mathrm{~m}^{-2}$. Readers are referred to Abernathey et al. (2011) for detailed motivation from observations for choosing the above forcing profiles. The purpose of the present study is to investigate the effect of different surface restoring time scales on the response of the Southern Ocean to wind stress changes, taking into account the qualitative arguments presented in Section 2.

The model was first spun up from rest with the above constant wind stress and heat flux forcing for 800 years to achieve a statistically steady state. After that, the model was run for another 300 years under the same wind stress forcing but with purely restoring surface heat flux forcing: the model surface temperature $\left(T_{s}\right)$ is restored to reference temperatures $\left(T_{\text {ref }}\right)$ at time scales of one day, one week, one month and half a year, respectively. The reference temperatures are determined in such a way that models with different restoring time scales have the same effective surface heat flux as the first 800-year spinup simulation, i.e.,

$$
T_{\text {ref }}=T_{s}+\frac{Q}{\rho_{0} c_{p} \lambda \Delta z},
$$

where $\Delta z=10 \mathrm{~m}$ is the thickness of the top model grid box, $c_{p}$ is specific heat at constant pressure, and $\lambda^{-1}$ is the restoring time scale. Here $T_{s}$ is taken to 
Table 2: Changes of surface eddy kinetic energy ( $\Delta \mathrm{EKE}$ in $\mathrm{m}^{2} \mathrm{~s}^{-2}$ ) in response to wind stress changes in model experiments with different surface restoring time scales. Note that $\lambda^{-1}=$ infinity corresponds to a fixed surface heat flux. The percentage change is relative to EKE at $\tau_{0}=0.2 \mathrm{~N} \mathrm{~m}^{-2}$.

\begin{tabular}{|c|c|c|c|c|}
\hline$\lambda^{-1}$ & $\begin{array}{c}\tau_{0}=0 \mathrm{~N} \mathrm{~m}^{-2} \\
\Delta \mathrm{EKE}(\%)\end{array}$ & $\begin{array}{c}\tau_{0}=0.1 \mathrm{~N} \mathrm{~m}^{-2} \\
\tau_{0}=0.2 \mathrm{~N} \mathrm{~m}^{-2}\end{array}$ & $\begin{array}{c}\tau_{0}=0.3 \mathrm{~N} \mathrm{~m}^{-2} \\
\mathrm{EKE}(\%)\end{array}$ & $\Delta \mathrm{EKE}(\%)$ \\
\hline 1 day & $-0.0046(-16 \%)$ & $-0.0024(-8.6 \%)$ & 0.0280 & $0.0034(12 \%)$ \\
\hline 1 week & & $-0.0053(-18 \%)$ & 0.0297 & $0.0047(16 \%)$ \\
\hline 1 month & & $-0.0072(-23 \%)$ & 0.0315 & $0.0065(21 \%)$ \\
\hline half a year & & $-0.0098(-30 \%)$ & 0.0327 & $0.0082(25 \%)$ \\
\hline infinity & $-0.0279(-85 \%)$ & $-0.0114(-35 \%)$ & 0.0330 & $0.0091(28 \%)$ \\
\hline
\end{tabular}

be the time-mean surface temperature averaged over the last 100 years of the first 800-year spinup. It is evident from (20) that the reference temperatures are different for model experiments with different surface restoring time scales (see Fig. 2d).

After this second stage of spinup, the models with different surface restoring time scales were run for another 300 years forced by wind stress of different strengths, i.e., different $\tau_{0}$ (see Table 2 for a list of model experiments conducted). Results averaged over the last 100 years are used for this study.

Following Abernathey et al. (2011) and Munday and Zhai (2013), the residual MOC, $\Psi_{\text {res }}$, is diagnosed by computing the time-mean streamfunction of the zonally-integrated thickness-weighted flow using the following integral,

$$
\Psi_{r e s}(y, \theta)=\frac{1}{\Delta t} \int_{t_{0}}^{t_{0}+\Delta t} \int_{0}^{L_{x}} \int_{\theta_{0}}^{\theta}(h v) d \theta d x d t,
$$

where $h=\partial z / \partial \theta$ is the layer thickness in potential temperature $(\theta)$ coordi- 
nate, $L_{x}$ is the zonal width of the channel, $t$ is time, and $\Delta t=100$ years. The integral in Eq. (21) is calculated using discrete layers that are $0.2^{\circ} \mathrm{C}$ thick with potential temperature used as the vertical coordinate, which is then converted back to depth coordinates. Finally, the eddy-induced MOC is diagnosed as the residual: $\Psi^{*}=\Psi_{\text {res }}-\bar{\Psi}=\Psi_{\text {res }}+\tau /\left(\rho_{0} f\right)$.

\section{Results}

\subsection{Spinup}

After the first 800-year spinup, the model reaches a statistically steady state and produces a vigorous eddy field, as demonstrated by the instantaneous surface temperature at the end of the spinup. Both the pattern and magnitude of the residual MOC averaged over the last 100 years of the spinup are very similar to those from the fixed surface flux experiment in Abernathey et al. (2011). The residual MOC is characterised by three distinct cells, and is, importantly, directed along the mean isotherms in the interior of the model domain (Fig. 3a), consistent with the assumption made in Section 2. These three overturning cells are closed by diabatic circulation in the surface diabatic and northern sponge layers. The branch of the broad upwelled water that travels north first gains buoyancy through surface heating but eventually encounters a region of surface cooling and subducts along the $4^{\circ} \mathrm{C}$ isotherm, forming the clockwise upper cell with a strength of $\sim 0.6 \mathrm{~Sv}$. The branch of the upwelled water that travels south quickly loses buoyancy due to surface heat loss and subducts along the $0.5^{\circ} \mathrm{C}$ isotherm, resulting in the coldest water in the domain and forming the counterclockwise deep cell with a strength of $\sim 0.2 \mathrm{~Sv}$. 
(a) Residual-mean MOC

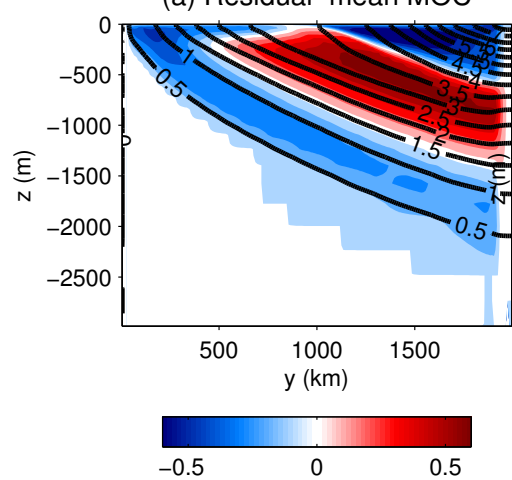

(b) Eulerian-mean MOC

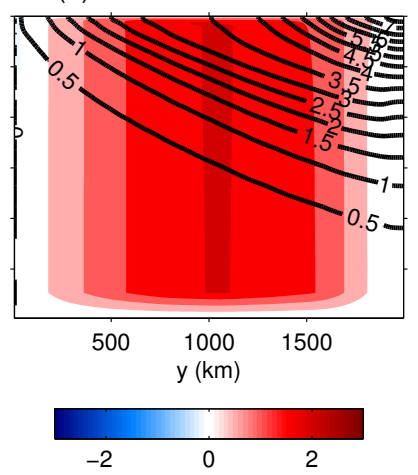

(c) Eddy-induced MOC

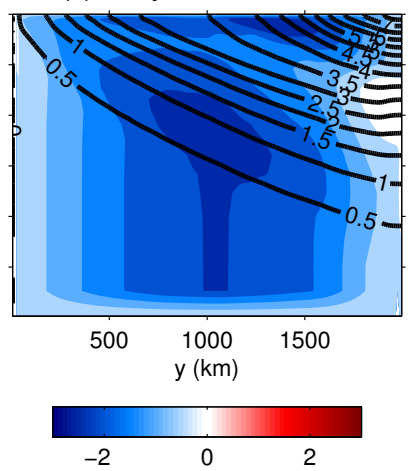

Figure 3: (a) The residual-mean, (b) Eulerian-mean and (c) eddy-induced MOCs averaged over the last 100 years of the first 800-year spinup model run in Sv. The black contours are the mean isotherms and the contour interval of the MOCs is $0.1 \mathrm{~Sv}$ in (a) but $0.5 \mathrm{~Sv}$ in (b) and (c).

These two overturning cells loosely resemble the gross circulation features observed in the Southern Ocean: upwelling of the North Atlantic Deep Water and subduction of the Antarctic Intermediate Water and Bottom Water (e.g. Rintoul et al., 2001), although it is worth emphasising the idealised nature of the model configuration. For example, bottom topography, which is known to play an important role in the formation of the deep cell in the Southern Ocean, is absent in this model. To the north of the upper cell, there is another counterclockwise overturning cell, but this cell is very shallow and contained mostly in the surface and northern diabatic layers. In this study, unless stated otherwise, we will focus primarily on the upper cell and its response to changes of wind stress. Figure 3 shows that the residual MOC results from cancellation of the much stronger Eulerian-mean MOC and eddyinduced MOC (see Eq. (2)). So far the first 800-year spinup has successfully reproduced the control experiment in Abernathey et al. (2011), albeit that 


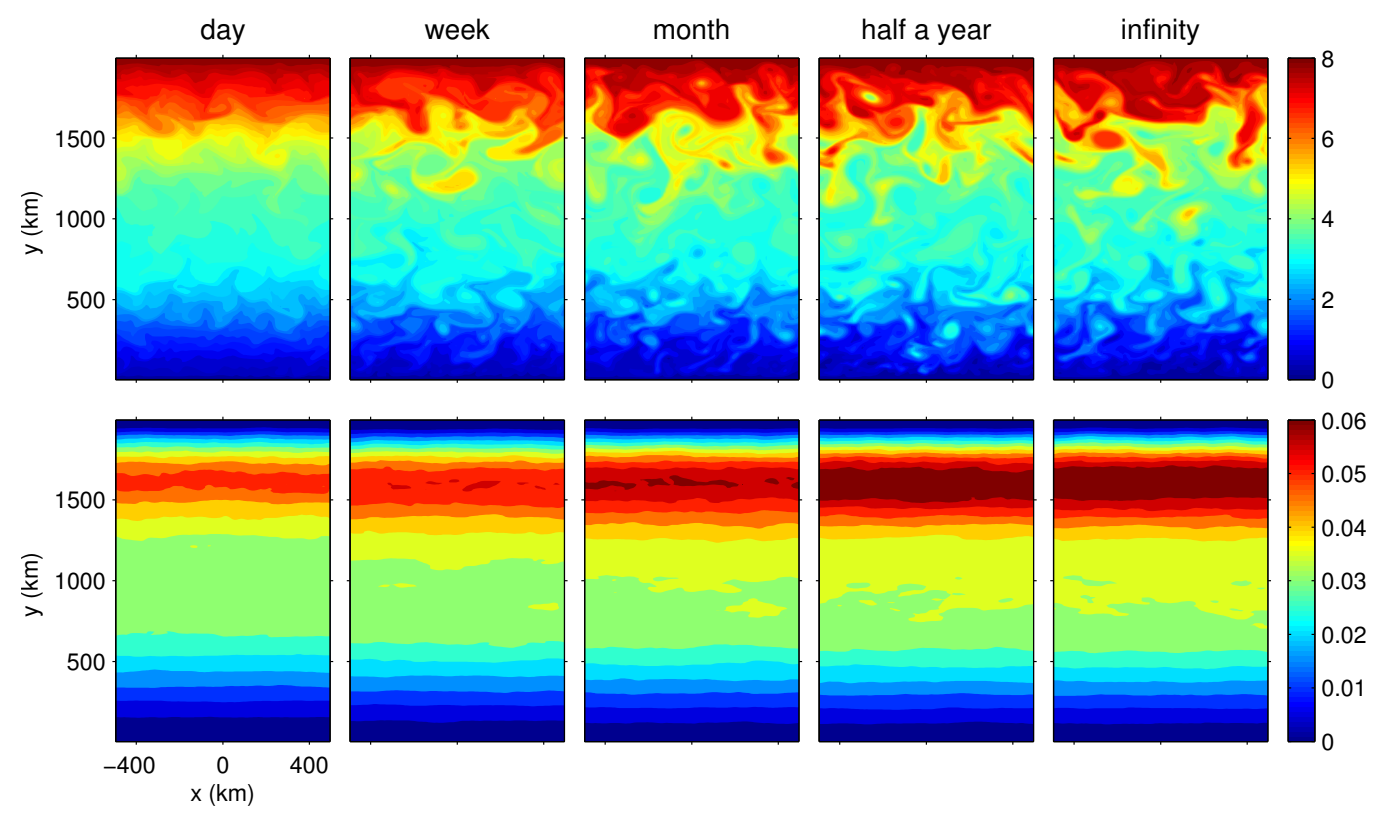

Figure 4: (The top row) The instantaneous surface temperature $\left({ }^{\circ} \mathrm{C}\right)$ at the end of the 300-year spinup with $\lambda^{-1}=1$ day, 1 week, 1 month, half a year and infinity, respectively, and (the bottom row) surface EKE $\left(\mathrm{m}^{2} \mathrm{~s}^{-2}\right)$ averaged over the last 100 years of this second stage of spinup.

the deep cell in our model is slightly weaker.

Over the next 300 years, the model is subject to the same wind stress forcing with $\tau_{0}=0.2 \mathrm{~N} \mathrm{~m}^{-2}$ but surface heat fluxes that result from restoring boundary conditions at various restoring time scales, $\lambda^{-1}$, ranging from one day to infinity (i.e., a fixed surface heat flux). Figure 4 shows the instantaneous surface temperature fields at the end of year 300 and surface EKE averaged over the last 100 years in model experiments with various $\lambda^{-1}$. As $\lambda^{-1}$ decreases from infinity to one day, surface temperature variability is increasingly damped owing to the increasingly efficient air-sea damping of surface eddy temperature variance (e.g. Zhai and Greatbatch, 2006b; Great- 
batch et al., 2007; Shuckburgh et al., 2011), although the time-mean surface temperature remains almost identical across all these experiments. The magnitude of surface EKE decreases everywhere with decreasing restoring time scale such that the surface EKE in the experiment with $\lambda^{-1}=1$ day is on average about $15 \%$ weaker than that in the experiment with $\lambda^{-1}=$ half a year. However, the influence of different surface restoring time scales on EKE decays rapidly with depth and becomes almost undetectable below the top $150 \mathrm{~m}$ (Fig. 5a). In contrast, the influence of air-sea damping on temperature variance extends at least twice as deep (Fig. 5b).

The net surface restoring heat fluxes in all these model experiments are similar to the constant surface heat flux used in the first 800-year spinup, although there are some differences when the restoring time scale becomes very short (not shown). Figure 6 shows the residual MOCs in experiments with different $\lambda^{-1}$. Apart from the differences in the surface diabatic layer, the residual MOCs in all the restoring model runs are comparable to each other, as well as to that in the first 800-year spinup (Fig. 3a).

\subsection{Response to wind stress changes}

After all the restoring model runs reach statistically steady states, we increase and decrease $\tau_{0}$ by $0.1 \mathrm{~N} \mathrm{~m}^{-2}$ and let the model run for another 300 years to reach a new equilibria. Figure 7 shows the changes of the residual MOCs averaged over the last 100 years when $\tau_{0}$ increases from 0.2 to 0.3 $\mathrm{N} \mathrm{m}^{-2}$. The increased wind stress is found to create anomalous clockwise overturning cells below the surface diabatic layer in all the restoring experiments. The strength and extent of these anomalous cells, however, varies with the restoring time scale, with greater changes seen for shorter restor- 
(a)

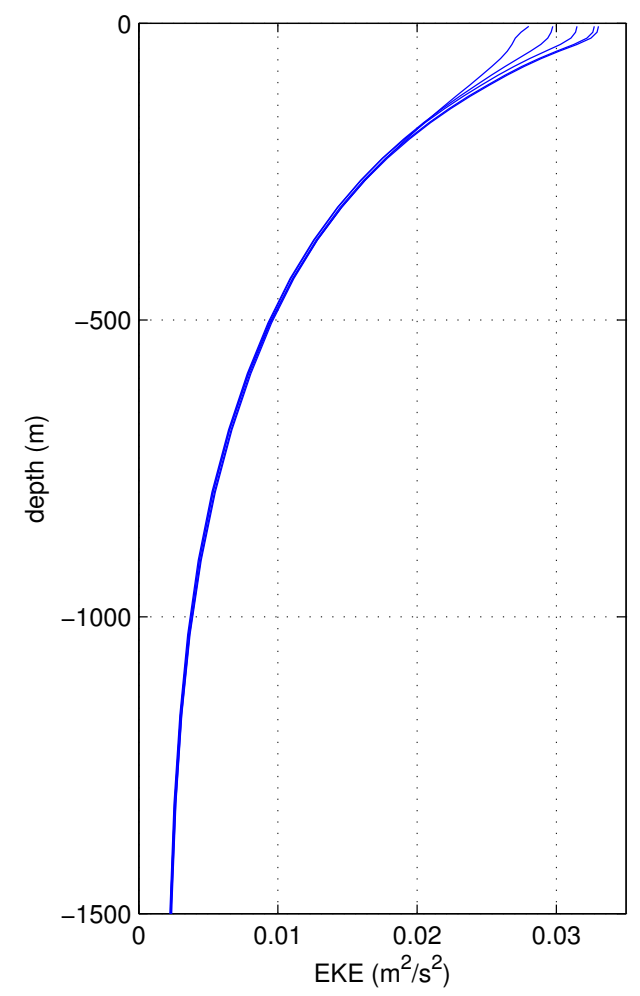

(b)

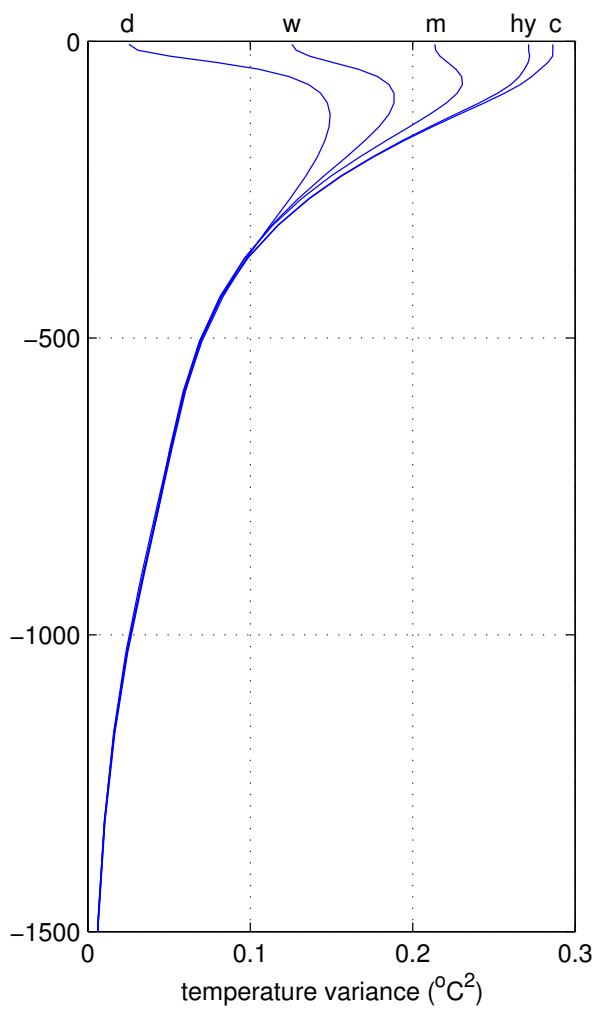

Figure 5: Horizontally-averaged (a) EKE $\left(\mathrm{m}^{2} \mathrm{~s}^{-2}\right)$ and (b) temperature variance $\left({ }^{\circ} \mathrm{C}^{2}\right)$ in the 300-year spinup model runs with various surface restoring time scales. Letters "d", "w", "m", "hf" and "c" denote model experiments with $\lambda^{-1}=1$ day, 1 week, 1 month, half a year, and infinity, respectively. The curves in (a) are in the same order as those in (b), but are not labelled for the sake of clarity. 

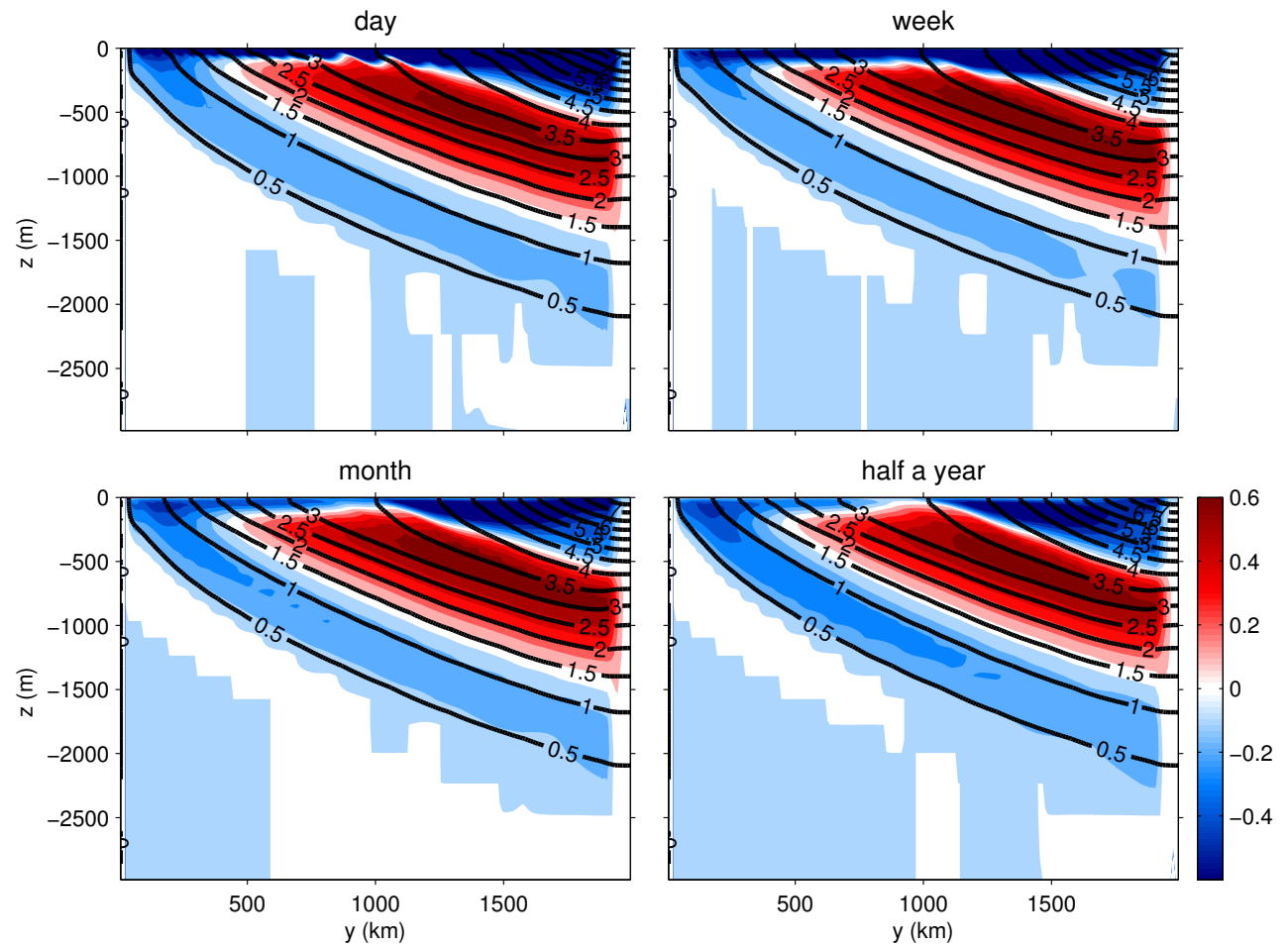

Figure 6: The residual MOCs (Sv) in the 300-year spinup model runs with $\lambda^{-1}=1$ day, 1 week, 1 month, and half a year, respectively. The black contours are the mean isotherms in each experiment and the contour interval of the MOCs is $0.1 \mathrm{~Sv}$. 

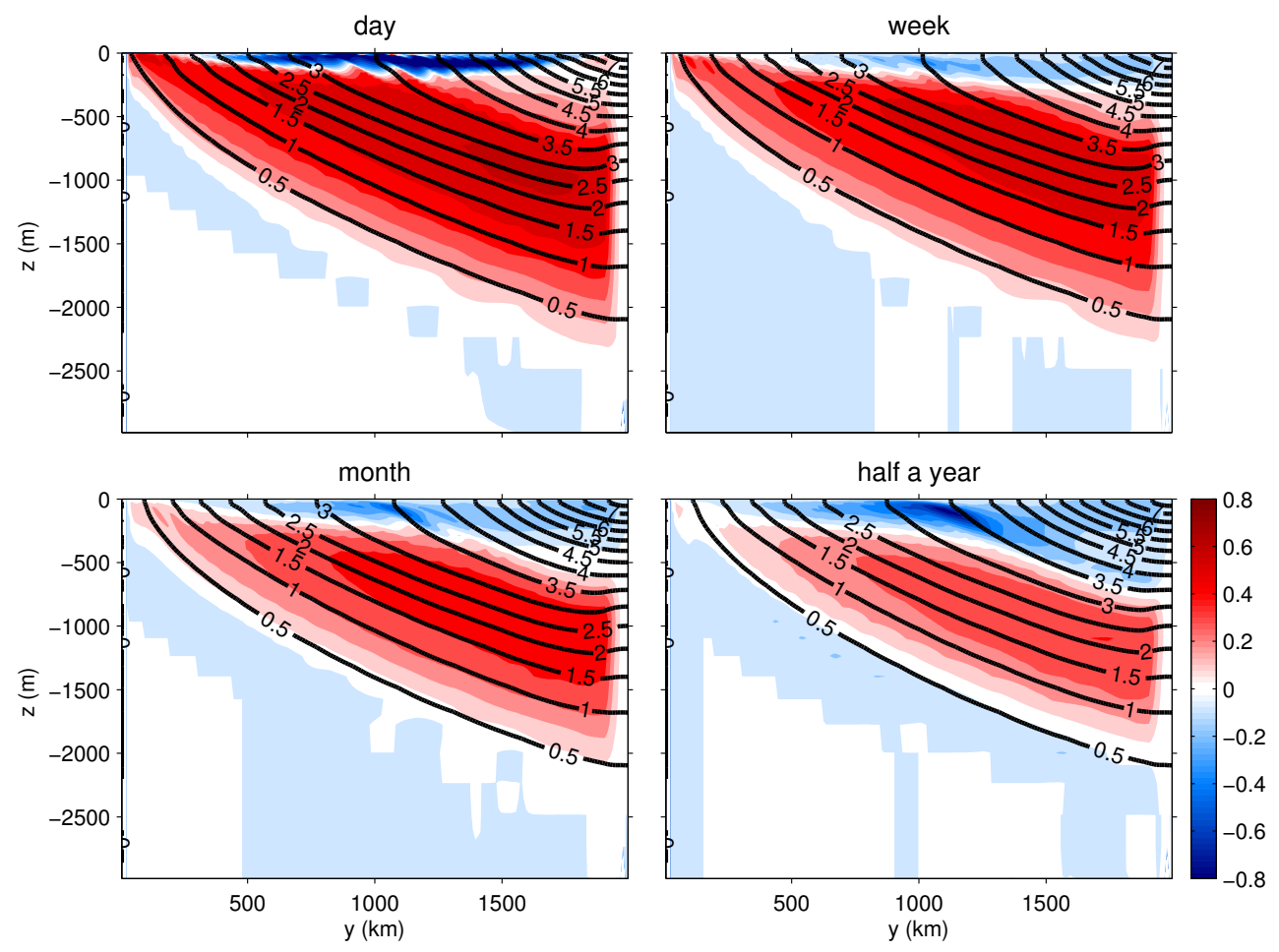

Figure 7: Changes of the residual MOCs (Sv) when the wind stress increases from 0.2 to $0.3 \mathrm{~N} \mathrm{~m}^{-2}$ in experiments with $\lambda^{-1}=1$ day, 1 week, 1 month, and half a year, respectively. The black contours are the mean isotherms in each experiment when $\tau_{0}=0.3 \mathrm{~N} \mathrm{~m}^{-2}$ and the contour interval of the MOCs is $0.1 \mathrm{~Sv}$. 
ing time scales. For example, the maximum changes associated with these anomalous cells in experiments with $\lambda^{-1}=1$ day, 1 week, 1 month and half a year are $0.69 \mathrm{~Sv}, 0.57 \mathrm{~Sv}, 0.48 \mathrm{~Sv}, 0.40 \mathrm{~Sv}$, respectively. Since the change in the Eulerian-mean MOCs $(\Delta \bar{\Psi} \simeq 1 \mathrm{~Sv}$ ) due to increased wind stress is identical across all the model experiments, differences in the response of the residual MOCs must be entirely due to differences in the response of the eddy-induced MOCs (Fig. 8).

The overall patterns of the response of the eddy-induced MOCs are very similar among experiments with different restoring time scales: $\Psi^{*}$ increases in strength in response to the increase in wind stress almost everywhere in the model domain. However, the magnitude of this increase in $\Psi^{*}$ is sensitive to the surface restoring time scale: longer $\lambda^{-1}$ results in a larger increase in $\Psi^{*}$. The magnitude of $\Psi^{*}$ is found to increase, on average, by about 0.2 Sv more, when $\lambda^{-1}=$ half a year than when $\lambda^{-1}=1$ day (Fig. $8 \mathrm{~d}$ minus Fig. 8a), excluding the top few tens of meters. Changes of the residual and eddy-induced MOCs when the wind stress weakens from 0.2 to $0.1 \mathrm{~N} \mathrm{~m}^{-2}$ generally mirror those when the wind stress strengthens from 0.2 to $0.3 \mathrm{~N}$ $\mathrm{m}^{-2}$ (not shown): larger decrease in the strength of $\Psi^{*}$ and thus smaller decrease of $\Psi_{\text {res }}$ at longer restoring time scales. The maximum changes of the residual MOCs in experiments with $\lambda^{-1}=1$ day, 1 week, 1 month and half a year are $-0.69 \mathrm{~Sv},-0.59 \mathrm{~Sv},-0.52 \mathrm{~Sv},-0.45 \mathrm{~Sv}$, respectively.

The response of the residual and eddy-induced MOCs to changes in wind stress as well as differences among experiments with different $\lambda^{-1}$ is broadly consistent with arguments presented in Section 2 for the strong and weak surface restoring limits. In the strong restoring limit, e.g., $\lambda^{-1}=1$ day, 
Table 3: Strength of the residual MOC of the upper cell (in Sv) below the surface diabatic layer in model experiments with different surface restoring time scales and wind forcing.

\begin{tabular}{|c|c|c|c|}
\hline$\lambda^{-1}$ & $\tau_{0}=0.1 \mathrm{~N} \mathrm{~m}^{-2}$ & $\tau_{0}=0.2 \mathrm{~N} \mathrm{~m}^{-2}$ & $\tau_{0}=0.3 \mathrm{~N} \mathrm{~m}^{-2}$ \\
\hline 1 day & 0.05 & 0.63 & 1.20 \\
\hline 1 week & 0.12 & 0.65 & 1.17 \\
\hline 1 month & 0.21 & 0.65 & 1.04 \\
\hline half a year & 0.36 & 0.64 & 0.88 \\
\hline infinity & 0.52 & 0.64 & 0.82 \\
\hline
\end{tabular}
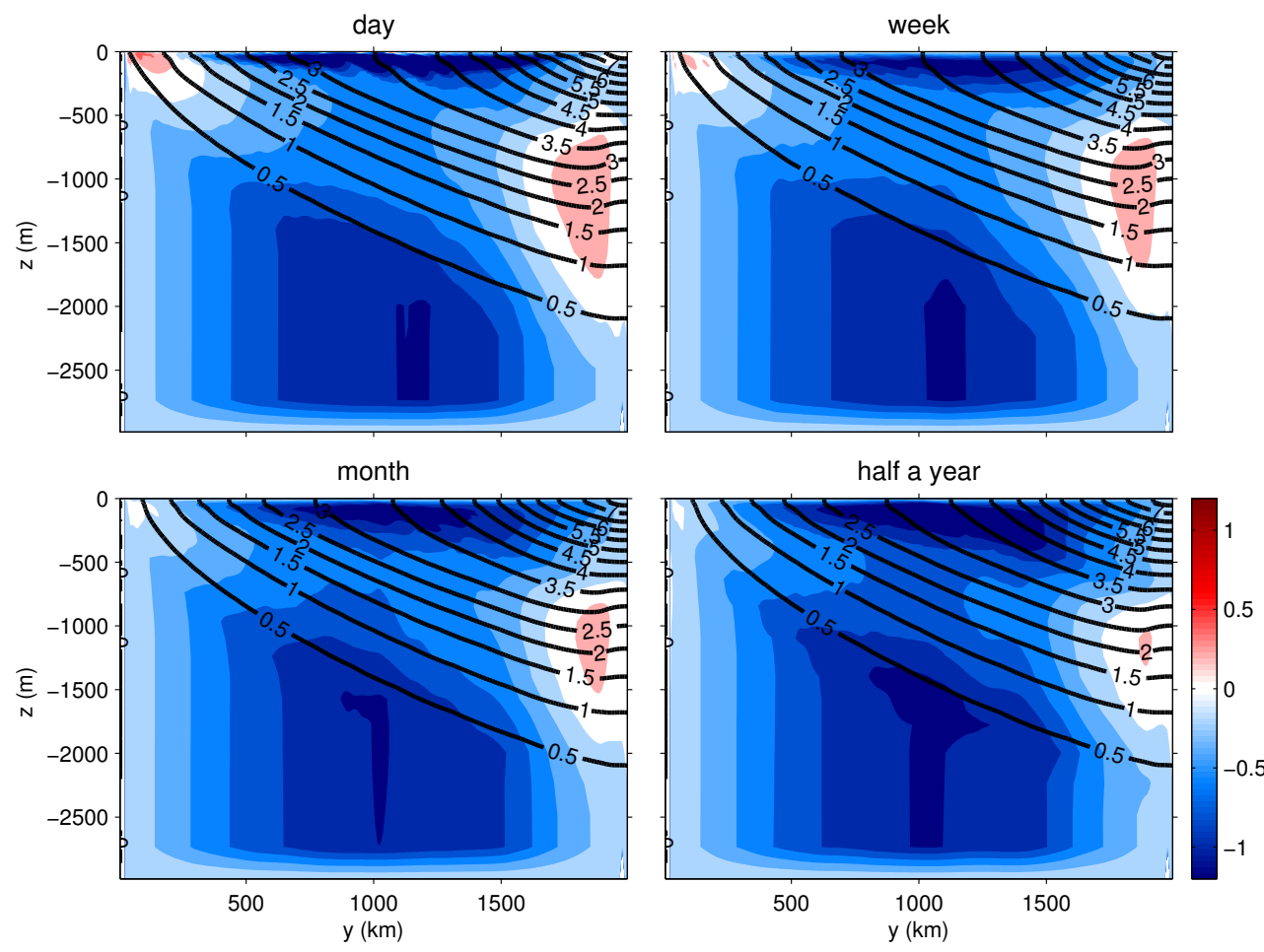

Figure 8: Changes of the eddy-induced MOCs $(\mathrm{Sv})$ when the wind stress increases from 0.2 to $0.3 \mathrm{~N} \mathrm{~m}^{-2}$ in experiments with $\lambda^{-1}=1$ day, 1 week, 1 month, and half a year, respectively. The black contours are the mean isotherms in each experiment when $\tau_{0}=0.3$ $\mathrm{N} \mathrm{m}^{-2}$ and the contour interval of the MOCs is $0.2 \mathrm{~Sv}$. 
temperature at the surface, as well as at the northern boundary, is effectively prescribed, leaving the isothermal slopes little freedom to vary (Fig. 9a). Since the eddy-induced MOC is, to a large extent, determined by the isothermal slopes according to the scaling argument in Section 2, changes of the eddy-induced MOC, and therefore the ability of eddies to compensate for changes of wind stress, are strongly suppressed. As a result, the residual MOC exhibits a greater sensitivity to wind stress changes when $\lambda^{-1}=1$ day.

As the restoring time scale lengthens, the isotherms at the surface become less constrained by the restoring and more able to move in response to wind stress changes (Figs. 9b-d). The isothermal slopes are thus increasingly free to steepen when the wind stress strengthens or slump when the wind stress weakens. This leads to a strengthening or weakening of the eddy field, which acts to compensate for wind stress changes. As a consequence, the residual MOC exhibits a much weaker sensitivity to wind stress changes when $\lambda^{-1}=$ half a year. The reduced sensitivity of the residual MOC at longer $\lambda^{-1}$ is consistent with the smaller changes of surface heat fluxes in experiments with longer $\lambda^{-1}$ (Fig. 10). Note that changes in surface heat fluxes in our experiments are results of the response of the Southern Ocean MOC to changes in wind stress such that in thermodynamic equilibrium the residual MOC matches the diabatic forcing (e.g. Walin, 1982; Watson and Naveira Garabato, 2006; Badin and Williams, 2010). Readers are referred to Morrison et al. (2011) for an example of the response of the Southern Ocean MOC to imposed changes in buoyancy forcing in the absence of wind stress changes.

Figure 11 shows changes of the horizontally-averaged EKE in experiments 

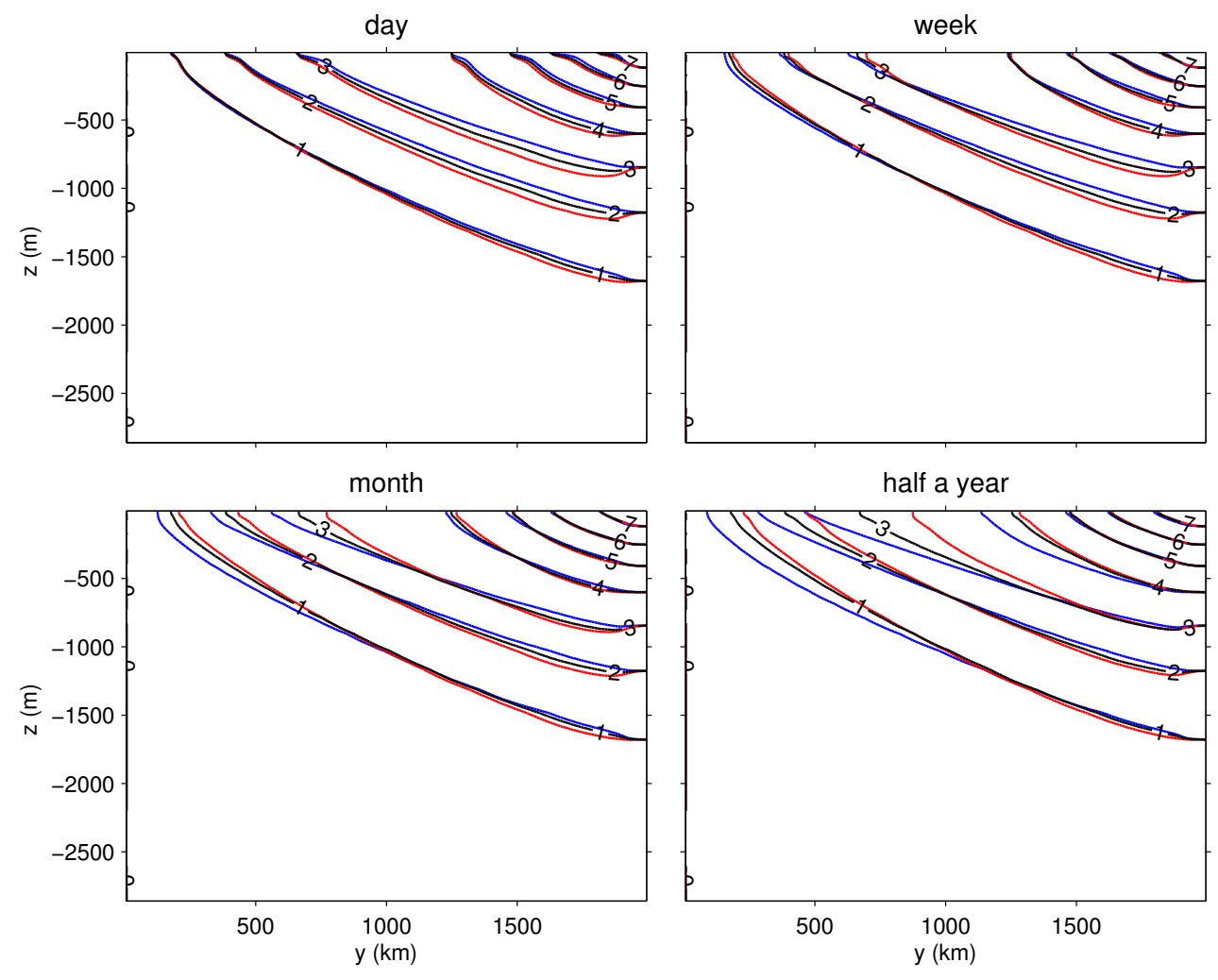

Figure 9: The time- and zonal-mean temperatures $\left({ }^{\circ} \mathrm{C}\right)$ in experiments with $\lambda^{-1}=1$ day, 1 week, 1 month, and half a year for $\tau_{0}=0.1 \mathrm{~N} \mathrm{~m}^{-2}$ (blue curve), $0.2 \mathrm{~N} \mathrm{~m}^{-2}$ (black curve), and $0.3 \mathrm{~N} \mathrm{~m}^{-2}$ (red curve). 


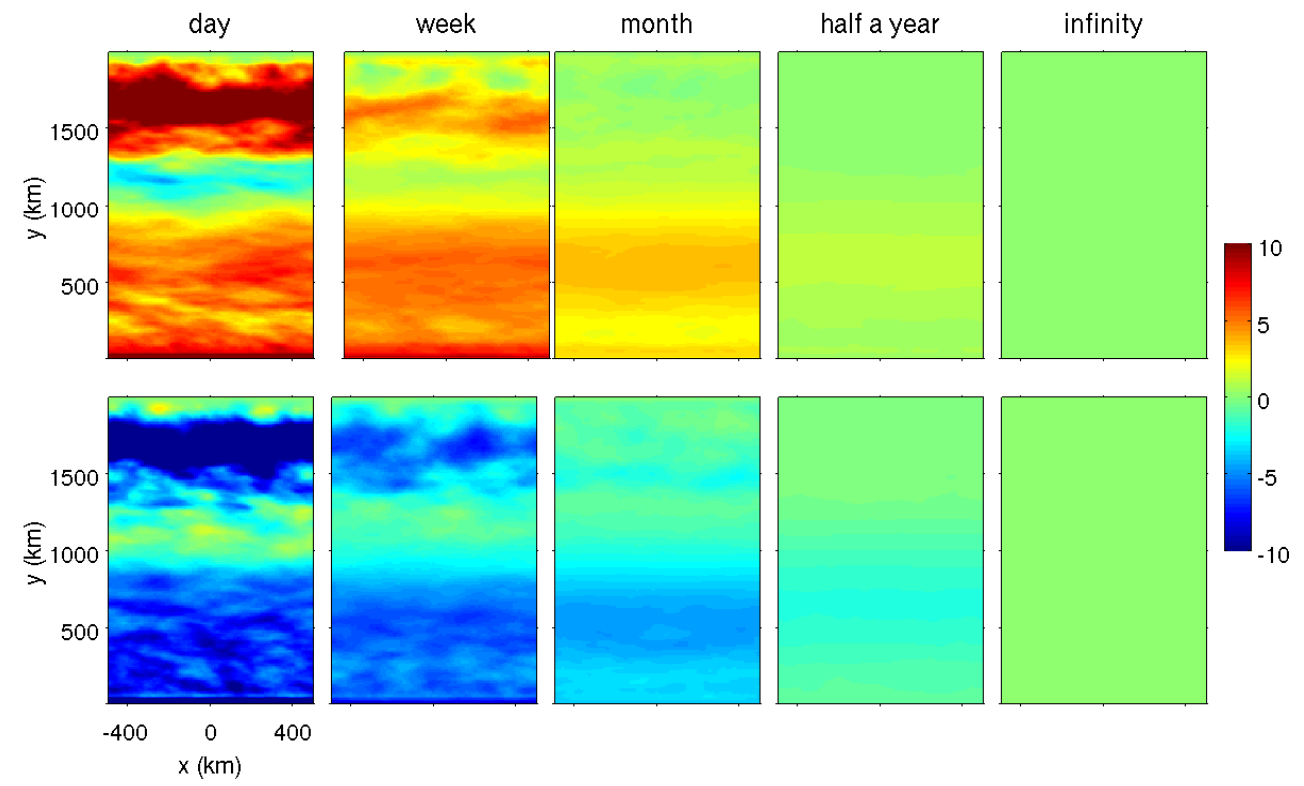

Figure 10: Changes of the net surface heat fluxes $\left(\mathrm{W} \mathrm{m}^{-2}\right)$ in experiments with $\lambda^{-1}=1$ day, 1 week, 1 month, half a year and infinity, when $\tau_{0}$ increases from 0.2 to $0.3 \mathrm{~N} \mathrm{~m}^{-2}$ (top row) and decreases from 0.2 to $0.1 \mathrm{~N} \mathrm{~m}^{-2}$ (bottom row). Positive values mean the ocean gains more heat. 


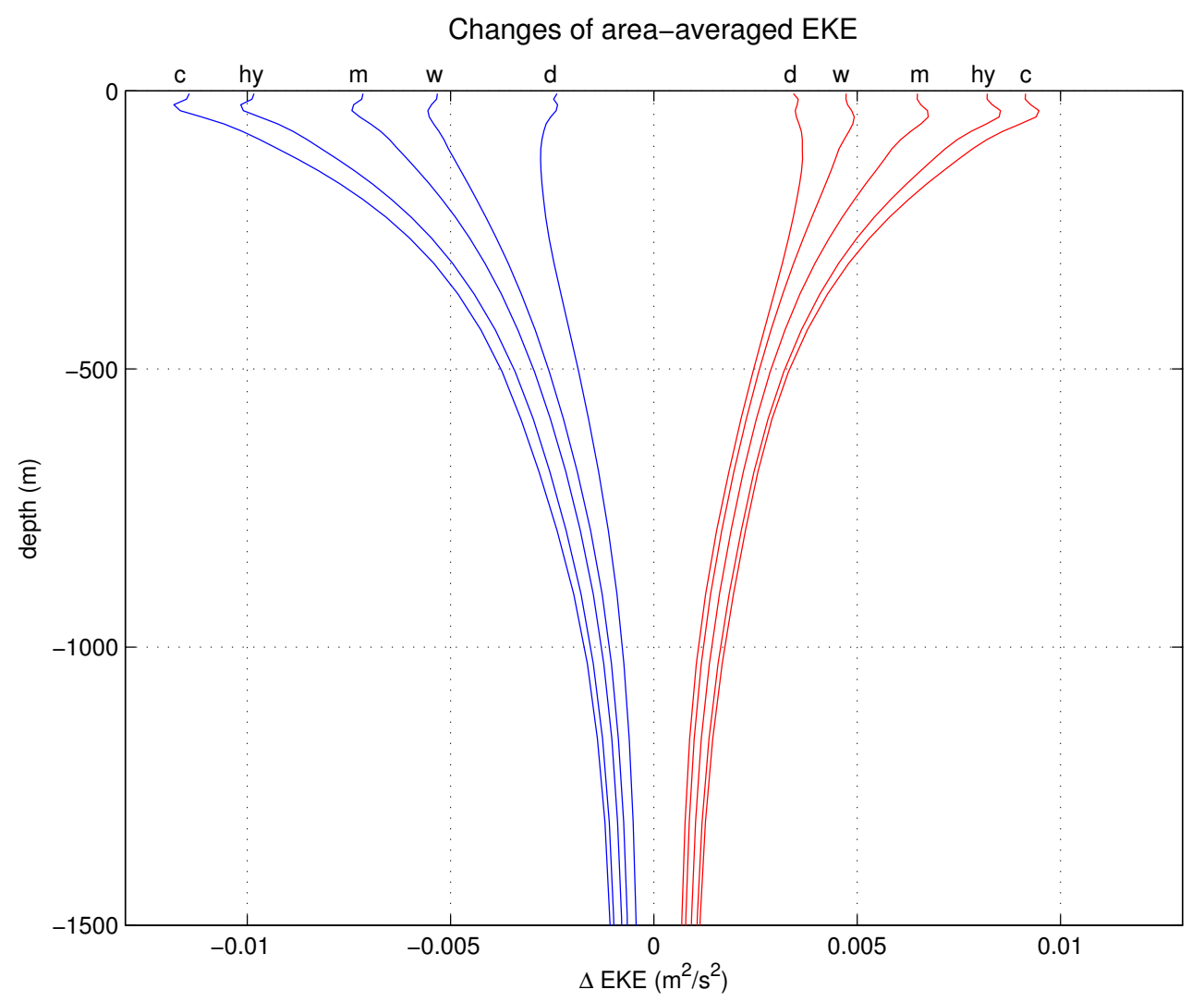

Figure 11: Changes of the horizontally-averaged EKE $\left(\mathrm{m}^{2} \mathrm{~s}^{-2}\right)$ when the wind stress increases from 0.2 to $0.3 \mathrm{~N} \mathrm{~m}^{-2}$ (red curves) and decreases from 0.2 to $0.1 \mathrm{~N} \mathrm{~m}^{-2}$ (blue curves). Letters "d", "w", "m", "hf" and "c" denote model experiments with $\lambda^{-1}=1$ day, 1 week, 1 month, half a year, and infinity, respectively. 
with different $\lambda^{-1}$, which clearly demonstrates the sensitivity of the eddy response to the surface restoring time scale. As the restoring time scale increases, EKE in our model becomes increasingly sensitive to wind stress changes. For example, in response to the strengthening of wind stress from 0.2 to $0.3 \mathrm{~N} \mathrm{~m}^{-2}$, EKE at the surface increases by $12 \%, 16 \%, 21 \%, 25 \%$ and $28 \%$ in experiments with $\lambda^{-1}=1$ day, 1 week, 1 month, half a year and infinity, respectively (see Table 2). A slightly greater change is seen when the wind stress relaxes from 0.2 to $0.1 \mathrm{~N} \mathrm{~m}^{-2}$, where the surface EKE is found to decrease by $8.6 \%, 18 \%, 23 \%, 30 \%$ and $35 \%$ in experiments with $\lambda^{-1}=1$ day, 1 week, 1 month, half a year and infinity, respectively. Note that changes of the EKE in response to wind stress changes are not confined in the upper ocean but extends all the way to the bottom, and so does the influence of different restoring time scales on such changes.

Adopting a simple flux gradient closure for the eddy buoyancy flux, the eddy diffusivity, $K(y, z)$, can be diagnosed using

$$
K(y, z)=-\frac{\overline{v^{\prime} T^{\prime}}}{\bar{T}_{y}},
$$

where $v^{\prime} T^{\prime}$ is the meridional eddy heat flux, $T_{y}$ is the meridional temperature gradient, overbars denote a 100-year average and primes are deviations from it. Figure 12 shows the zonally-averaged $K$ for different values of $\tau_{0}$ at $\lambda^{-1}=1$ day and $\lambda^{-1}=$ infinity, respectively. Similar to Abernathey et al. (2011), $K$ is found to be intensified near the very surface and toward the bottom, with a minimum at mid-depth. The magnitude of $K$ increases with increasing wind stress for all $\lambda^{-1}$, but the spatial pattern of $K$ does not appear to be sensitive to either $\tau_{0}$ or $\lambda^{-1}$. The degree of changes in $K$ in response to changes in wind stress, however, depends on $\lambda^{-1}$, with greater 

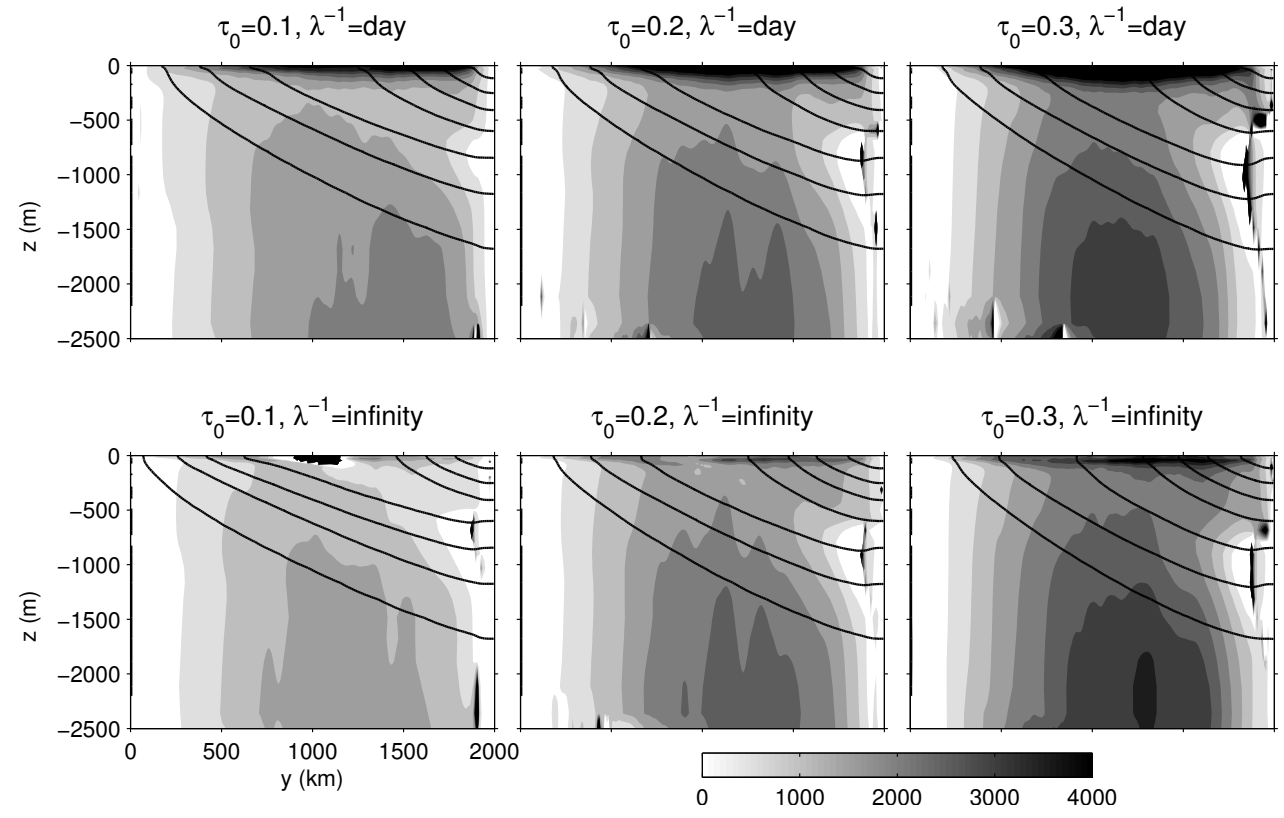

Figure 12: Zonally-averaged eddy thickness diffusivity $K(y, z)$ with contour interval of $500 \mathrm{~m}^{2} \mathrm{~s}^{-1}$ in experiments with $\lambda^{-1}=1$ day (top row) and $\lambda^{-1}=$ infinity (bottom row), respectively. The black contours are the mean isotherms in each experiment, and the contour interval is $1^{\circ} \mathrm{C}$. 

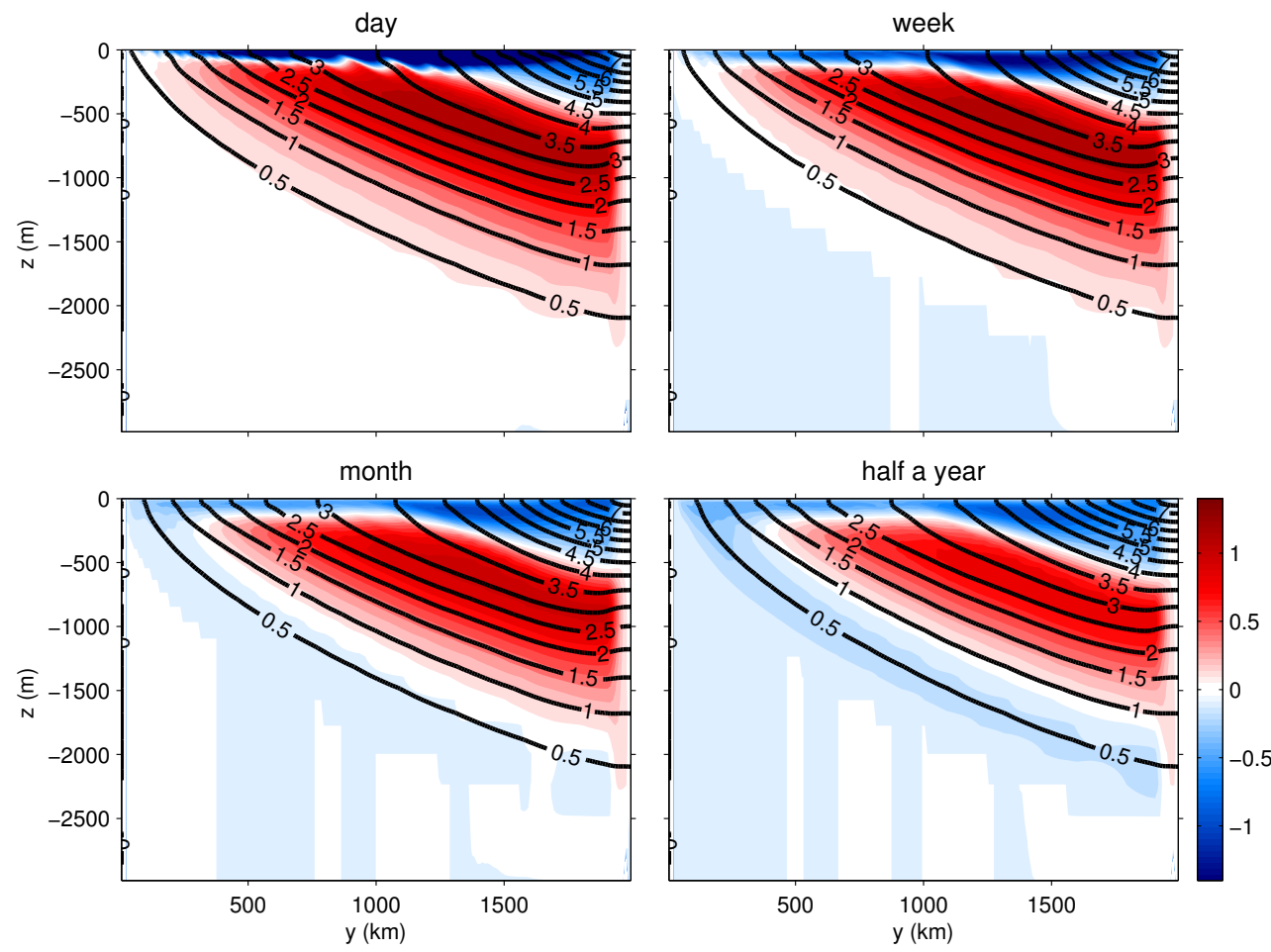

Figure 13: The residual MOCs (Sv) when $\tau_{0}=0.3 \mathrm{~N} \mathrm{~m}^{-2}$ in experiments with $\lambda^{-1}=$ 1 day, 1 week, 1 month, and half a year, respectively. The black contours are the mean isotherms in each experiment and the contour interval of the MOCs is $0.1 \mathrm{~Sv}$.

changes found at longer $\lambda^{-1}$. For example, when $\tau_{0}$ decreases from 0.2 to $0.1 \mathrm{~N} \mathrm{~m}^{-2}, K$ decreases on average by about $600 \mathrm{~m}^{2} \mathrm{~s}^{-1}$ in experiment with $\lambda^{-1}=1$ day, but by more than $900 \mathrm{~m}^{2} \mathrm{~s}^{-1}$ in experiment with $\lambda^{-1}=$ infinity. The greater sensitivity of $K$ to wind stress changes at longer $\lambda^{-1}$ is consistent with the greater sensitivities of isothermal slopes and EKE at longer $\lambda^{-1}$ as well as the scaling arguments presented in Section 2.

We now come back to interpret the residual MOCs in experiments with different $\lambda^{-1}$ when the wind stress strengthens (Fig. 13). At $\lambda^{-1}=1$ day, 
the lower cell disappears and the upper cell becomes significantly stronger, resulting in an overall clockwise cell below the surface diabatic layer. With the wind stress increasing to $0.3 \mathrm{~N} \mathrm{~m}^{-2}$, the strength of the Eulerian-mean MOC increases by $1 \mathrm{~Sv}$, that is, a $50 \%$ increase. On the other hand, the vigour of eddy activity is maintained by the sloping isotherms that are held more or less constant by strong restoring at the surface as well as at the northern boundary, regardless of the increase in wind stress. Table 2 shows that the surface EKE increases by only $12 \%$, and is thus unable to keep up with wind stress changes. In the case of an increase in wind stress, restoring at the surface acts as an extra energy sink for the system by preventing the isotherms from tilting further. As a result, the strength of the residual MOC below the surface diabatic layer becomes almost doubled, increasing by 0.57 $\mathrm{Sv}$ (see Table 3). Note that this is less than the maximum increase of 0.69 $\mathrm{Sv}$ found in Fig. 7a because the maximum increase of the residual MOC (Fig. 7a) and the maximum residual MOC itself (Fig. 6a) do not overlap in space. Apparently even at $\lambda^{-1}=1$ day there is still some eddy compensation effect, and as such the increase of the residual MOC is still less than the 1 Sv increase of the Eulerian-mean MOC. At $\lambda^{-1}=$ half a year, when the wind stress increases to $0.3 \mathrm{~N} \mathrm{~m}^{-2}$, the isothermal slopes become steeper, which leads to an enhanced eddy activity that is able to compensate for the majority of the increase in the Eulerian-mean MOC. For example, the surface EKE increases by about 25\% (Table 2), more than double of the percentage increase when $\lambda^{-1}=1$ day. As a result, the strength of the residual MOC below the surface diabatic layer increases only by about $0.24 \mathrm{~Sv}$ (Table 3), less than half of the increase when $\lambda^{-1}=1$ day. Furthermore, the pattern of 

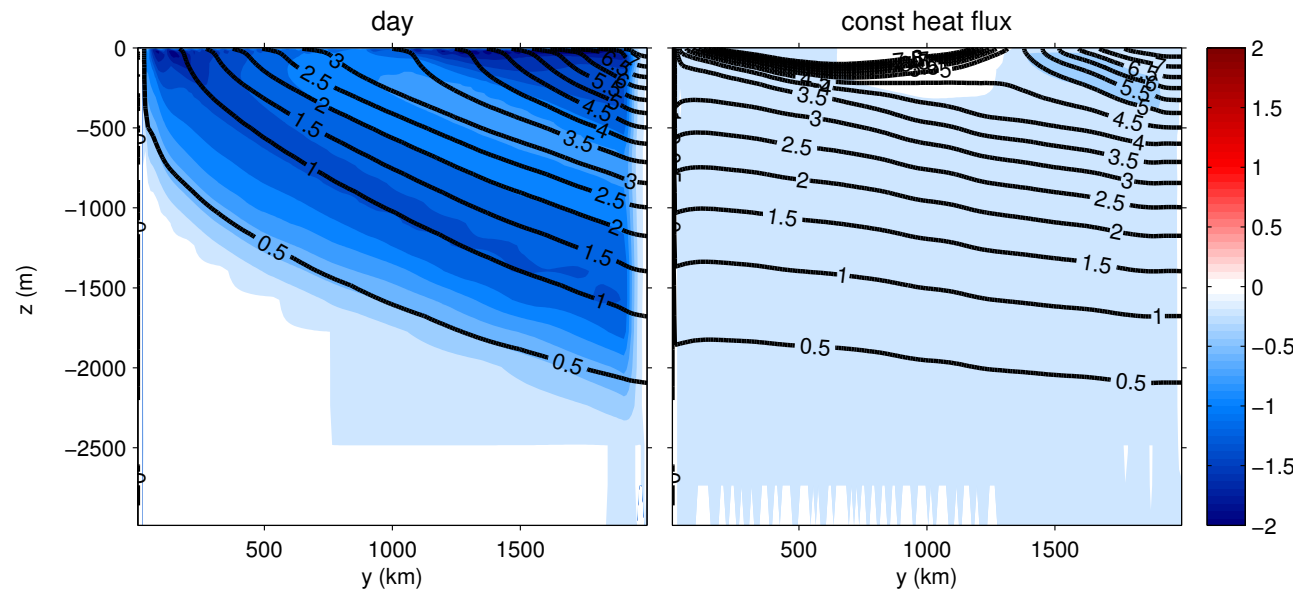

Figure 14: The residual MOCs (Sv) when the wind stress vanishes in experiments with $\lambda^{-1}=1$ day and $\lambda^{-1}=$ infinity. The black contours are the mean isotherms in each experiment and the contour interval of the MOCs is $0.2 \mathrm{~Sv}$.

the residual MOC in the case of $\lambda^{-1}=$ half a year (Fig. 13d) resembles that when $\tau_{0}=0.2 \mathrm{~N} \mathrm{~m}^{-2}$ (Fig. 6d).

Two additional model experiments were conducted with zero wind stress and at two restoring limits, i.e., $\lambda^{-1}=1$ day and $\lambda^{-1}=$ infinity, respectively (Fig. 14). Since the Eulerian-mean MOC vanishes with zero wind stress, the residual MOC is driven entirely by eddies. In the experiment where $\lambda^{-1}=1$ day, the residual MOC is characterised by an overall counterclockwise circulation above the $0.5^{\circ} \mathrm{C}$ isotherm. Note that the eddy-induced $\mathrm{MOC}$ with vanishing wind stress is now directed along the mean isotherms in the interior of the model domain, in contrast to the situation where the wind stress is finite (Fig. 3c). Strong restoring at the surface is clearly capable of maintaining a vigorous residual MOC by supplying mean APE to the system and acting as an energy source for eddies. At $\lambda^{-1}=1$ day, the surface EKE in 
the experiment with vanishing wind stress is only $16 \%$ weaker than that in the experiment where $\tau_{0}=0.2 \mathrm{~N} \mathrm{~m}^{-2}$ (Table 2). In contrast, in the experiment with a fixed surface heat flux, i.e., $\lambda^{-1}=$ infinity, the isotherms become almost flat below the surface diabatic layer. There is only a weak residual MOC associated with a weak eddy field generated by constant surface heating and cooling (e.g. Munday and Zhai, 2013). With a fixed surface heat flux, the surface EKE in the experiment with vanishing wind stress is about $85 \%$ less than that in the experiment where $\tau_{0}=0.2 \mathrm{~N} \mathrm{~m}^{-2}$ (Table 2).

\section{Summary and Discussion}

In this study, we have investigated the influence of different surface restoring times scales on the response of the Southern Ocean overturning to changes of the wind forcing, extending the recent work by Abernathey et al. (2011). Results from our idealised eddy-permitting model experiments broadly agree with the simple arguments derived from the residual-mean framework of Marshall and Radko (2003). Regardless of the restoring time scale chosen, the eddy-induced MOC is found to compensate for changes of the direct winddriven Eulerian-mean MOC, rendering the residual MOC less sensitive than the Eulerian-mean MOC to wind stress changes. Our results thus add support to the concept of eddy compensation (Viebahn and Eden, 2010). However, the extent of this compensation depends strongly on the surface restoring time scale: residual MOC sensitivity increases with decreasing restoring time scale. Since changes of the Eulerian-mean MOCs are almost identical in experiments with different restoring time scales, the different degrees of compensation are due entirely to differences in the response of the eddy-induced 
MOCs to wind stress changes.

The picture that emerges from our model study is as follows. The increase in wind stress enhances the Eulerian-mean MOC that acts to further steepen the tilted isopycnals and increase the mean APE of the system. In the case of weak surface restoring, the isopycnals at the surface are free to move around and as such the isopycnal surfaces steepen, which leads to the generation of a more vigorous eddy field. The associated enhanced eddyinduced MOC opposes the increase in the Eulerian-mean MOC, resulting in smaller changes in the residual MOC. In contrast, in the case of strong surface restoring, the isopycnals at the surface are pinned there, unable to move around in response to wind stress changes, and the isopycnal surfaces consequently do not steepen. The action of wind stress to increase the mean APE is directly counterbalanced by surface restoring, leaving the eddy field largely unchanged. As a result, the eddy-induced MOC is unable to keep up with the increase in the Eulerian-mean MOC, leading to a higher degree of sensitivity of the residual MOC. The impact of surface restoring is particularly striking in experiments with vanishing wind stress, where restoring at a short time scale is found to be capable of maintaining an eddy-induced MOC of considerable strength by supplying mean APE to the system.

In addition to the eddy compensation effect on the MOC, recent eddyresolving and eddy-permitting model studies (e.g. Hallberg and Gnanadesikan, 2006; Farneti et al., 2010; Munday et al., 2013) show that the presence of eddies also significantly limits the sensitivity of the Antarctic Circumpolar Current (ACC) volume transport in response to changes in wind stress. For example, the ACC transport increases by only about $10 \%$ to $20 \%$ in most 
eddy-permitting models when the Southern Ocean wind stress is doubled. This phenomenon is termed eddy saturation (Straub, 1993).

Eddy saturation and eddy compensation are often believed to be dynamically linked: changes of the eddy-induced MOC compensate for changes of the direct wind-driven MOC, reduces the increase in the tilt of the isopycnals, and thereby limits the sensitivity of the (baroclinic) ACC transport through thermal wind relation. The implication is that if the ACC transport is eddy saturated, the Southern Ocean MOC is also eddy compensated. However, in a recent idealised model study at both eddy-permitting and eddy-resolving resolutions, Morrison and Hogg (2013) found significant differences between the sensitivities and the resolution dependence of the Southern Ocean MOC and the ACC transport in response to wind stress changes and they suggested that eddy saturation and eddy compensation are controlled by distinct dynamical mechanisms.

Results from our simple model corroborate the findings of Morrison and Hogg (2013): there is no one-to-one relationship between eddy saturation and eddy compensation. At the shorter surface restoring time scale, the (baroclinic) ACC transport in our model is insensitive (or saturated) to wind stress changes owing to the largely prescribed isopycnal slopes, whereas the RMOC varies considerably and is clearly less eddy compensated. At the longer restoring time scale, the (baroclinic) ACC transport becomes more variable, i.e., less saturated, owing to changes of the isopycnal slopes, while the RMOC becomes much more eddy-compensated. Interestingly, our simple model suggests that the degrees of eddy saturation and eddy compensation vary in the opposite sense as a function of the surface restoring time scale. 
This distinction between eddy saturation and eddy compensation bears significance for interpreting past and future observations. For example, Böning et al. (2008) analysed the Argo network of profiling floats and historical oceanographic data and found no increase in the tilt of isopycnals across the ACC in spite of the observed significant intensification of the Southern Ocean westerlies. From these observations, they concluded that both the ACC transport and the Southern Ocean MOC are insensitive to recent changes in wind stress. Results from our simple model experiments suggest that the lack of observational evidence for changes in isopycnal slope may mean that the ocean is in a strong restoring limit. If this is the case, then the residual MOC may have actually changed significantly, although such change is hard to observe. In contrast, if a large change in isopycnal slope was detected, this does not necessarily mean that the residual MOC must change similarly - the ocean may be in a weak restoring limit.

For this study, we have chosen to use the idealised model setup of Abernathey et al. (2011) because it provides a simple yet physically-appealing framework. No topography and fixed stratification imposed at the northern boundary are probably the most severe limitations of this model (see Abernathey et al. (2011) for detailed discussions). At shorter restoring time scales, the deepening of the isotherms due to increasing wind stress appears to be arrested by the sponge layer imposed at the northern boundary (Fig. 9), rendering the mean isothermal slopes less sensitive to wind stress changes. However, this does not necessarily mean the sensitivity to the surface restoring time scale would be reduced if there were ocean basins to the north of the channel model. In the ocean, we expect these thermocline depth anomalies 
on the northern flank of the ACC to propagate to the rest of the ocean via boundary and Rossby wave adjustment processes and to be absorbed by the vast surface area of ocean basins to the north (e.g. Allison et al., 2011). This implies that the surface restoring time scale in the Southern Ocean may play a role in regulating the depth of the global pycnocline. Efforts are currently underway to include ocean basins further to the north of the channel as well as bottom topography.

A major motivation for the present study is the uncertainty associated with the surface restoring time scale owing to the lack of observations. For example, studies based on heat flux data derived from ship and satellite observations suggest that the restoring time scales can vary from less than one month to almost one year in the Southern Ocean, depending on season and location (e.g. Park et al., 2005). In another observation-based study, Zhai and Greatbatch (2006a) found considerable uncertainty and spatial variability of the surface restoring time scale, ranging from a few days in the Gulf Stream region to over several months in the interior of the subtropical gyre. The strong dependence of the Southern Ocean response to wind stress changes on the surface restoring time scale found in the present study points to the importance of accurately estimating the effect of surface turbulent heat fluxes on sea surface temperature anomalies as well as air-sea buoyancy fluxes in general.

\section{Acknowledgements}

Numerical model experiments were carried out on the High Performance Computing Cluster supported by the Research and Specialist Computing 
Support service at the University of East Anglia. We thank Andy Hogg, David Marshall, and two anonymous reviewers for valuable comments.

\section{References}

Abernathey, R., Marshall, J., Ferreira, D., 2011. The dependence of Southern Ocean meridional overturning on wind stress. J. Phys. Oceanogr. 41, 22612278 .

Allison, L. C., Johnson, H. L., Marshall, D. P., 2011. Spin-up and adjustment of the Antarctic Circumpolar Current and global pycnocline. J. Mar. Res. 69, 167-189.

Anderson, R. F., Ali, S., Bradtmiller, L. I., Nielsen, S. H. H., Fleisher, M. Q., Anderson, B. E., Burckle, L. H., 2009. Wind-driven upwelling in the Southern Ocean and the deglacial rise in atmospheric $\mathrm{CO}_{2}$. Science 323, 11431150.

Badin, G., Williams, R. G., 2010. On the buoyancy forcing and residual circulation in the Southern Ocean: The feedback from Ekman and eddy transfer. J. Phys. Oceanogr. 40, 295-311.

Böning, C. W., Dispert, A., Visbeck, M., Rintoul, S. R., Schwarzkopf, F. U., 2008. The response of the Antarctic Circumpolar Current to recent climate change. Nat. Geosci. 1, 864-869.

Bretherton, F. P., 1982. Ocean climate modeling. Prog. Oceanogr. 11, 93129. 
Chang, E. K. M., Guo, Y., Xia, X., 2012. CMIP5 multimodel ensemble projection of storm track change under global warming. J. Geophys. Res. 117.

Farneti, R., Delworth, T. L., Rosati, A. J., Griffies, S. M., Zeng, F., 2010. The role of mesoscale eddies in the rectification of the Southern Ocean response to climate change. J. Phys. Oceanogr. 40, 1539-1557.

Frankignoul, C., 1985. Sea surface temperature anomalies, planetary waves and air-sea feedback in the midlde latitudes. Rev. Geophys. 23, 357-390.

Fyfe, J. C., Saenko, O. A., 2006. Simulated changes in the extratropical Southern Hemisphere winds and currents. Geophys. Res. Lett. 33.

Greatbatch, R. J., Zhai, X., Eden, C., Olbers, D., 2007. The possible role in the ocean heat budget of eddy-induced mixing due to air-sea interaction. Geophys. Res. Lett. 34.

Hallberg, R., Gnanadesikan, A., 2006. The role of eddies in determining the structure and response of the wind-driven southern hemisphere ouverturning: Results from Modeling Eddies in the Southern Ocean (MESO) project. J. Phys. Oceanogr. 36, 2232-2252.

Haney, R., 1971. Surface thermal boundary condition for ocean circulation models. J. Phys. Oceanogr. 1, 241-248.

Large, W. G., McWilliams, J. C., Doney, S. C., 1994. Oceanic vertical mixing: A review and a model with a nonlocal boundary layer parmeterization. Rev. Geophys. 32, 363-403. 
Marshall, D. P., 1997. Subduction of water masses in an eddying ocean. J. Mar. Res. 55, 201-222.

Marshall, D. P., Maddison, J. R., Berloff, P. S., 2012. A framework for parameterizing eddy potential vorticity fluxes. J. Phys. Oceanogr. 42, 539-557.

Marshall, J., Adcroft, A., Hill, C., Perelman, L., Heisey, C., 1997. A finitevolume, incompressible Navier Stokes model for studies of the ocean on parallel computers. J. Geophys. Res. 102, 5753-5766.

Marshall, J., Radko, T., 2003. Residual-mean solutions for the Antarctic Circumpolar Current and its associated overturning circulation. J. Phys. Oceanogr. 33, 2341-2354.

Marshall, J., Speer, K., 2012. Closure of the meridional overturning circulation through Southern Ocean upwelling. Nature Geo. 5, 171-180.

Meredith, M. P., Hogg, A. M., 2006. Circumpolar response of Southern Ocean eddy activity to a change in the Southern Hemisphere Mode. Geophys. Res. Lett. 33.

Meredith, M. P., Naveira Garabato, A. C., Hogg, A. M., Farneti, R., 2012. Sensitivity of the overturning circulation in the Southern Ocean to decadal changes in wind forcing. J. Climate 25, 99-110.

Morrison, A. K., Hogg, A. M., 2013. On the relationship between Southern Ocean overturning and ACC transport. J. Phys. Oceanogr. 43, 140-148.

Morrison, A. K., Hogg, A. M., Ward, M. L., 2011. Sensitivity of the Southern 
Ocean overturning circulation to surface buoyancy forcing. Geophys. Res. Lett. 38.

Munday, D. R., Allison, L. C., Johnson, H. L., Marshall, D. P., 2011. Remote forcing of the Antarctic Circumpolar Current by diapycnal mixing. Geophys. Res. Lett. 38.

Munday, D. R., Johnson, H. L., Marshall, D. P., 2013. Eddy saturation of equilibrated circumpolar currents. J. Phys. Oceanogr. 43, 507-532.

Munday, D. R., Zhai, X., 2013. Modulation of eddy kinetic energy, temperature variance, and eddy heat fluxes by surface buoyancy forcing. Ocean Modell. 62, 27-38.

Park, S., Deser, C., Alexander, M. A., 2005. Estimation of the surface heat flux response to sea surface temperature anomalies over the global oceans. J. Climate 18, 4582-4599.

Rintoul, S., Hughes, C., Olbers, D., 2001. The Antarctic Circumpolar Current system. In: Sielder, G., Church, J., Gould, J. (Eds.), Ocean Circulation and Climate. Academic Press, pp. 171-302.

Shuckburgh, E., Maze, G., Ferreira, D., Marshall, J., Jones, H., Hill, C., 2011. Mixed layer lateral eddy fluxes mediated by air-sea interaction. J. Phys. Oceanogr. 41, 130-144.

Smith, K. S., 2007. The geography of linear baroclinic instability in Earth's oceans. J. Mar. Res. 65, 655-683. 
Solomon, S., Qin, D., Manning, M., Marquis, M., Averyt, K., Tignor, M. M. B., Miller, H. L., Chen, Z. (Eds.), 2007. Climate Change 2007: The Physical Science Basis. Cambridge University Press, p. 996 pp.

Straub, D., 1993. On the transport and angular momentum balance of channel models of the Antarctic Circumpolar Current. J. Phys. Oceanogr. 23, 776-783.

Toggweiler, J. R., Russell, J., 2008. Ocean circulation in a warming climate. Nature 451, 286-288.

Viebahn, J., Eden, C., 2010. Towards the impact of eddies on the response of the Southern Ocean to climate change. Ocean Modell. 34, 150-165.

Visbeck, M., Marshall, J., Haine, T., Spall, M., 1997. On the specification of eddy transfer coefficients in coarse resolution ocean circulation models. J. Phys. Oceanogr. 27, 381-402.

Walin, G., 1982. On the relation between sea-surface heat flow and thermal circulation in the ocean. Tellus 34, 187-195.

Watson, A. J., Naveira Garabato, A. C., 2006. The role of Southern Ocean mixing and upwelling in glacial-interglacial atmospheric $\mathrm{CO}_{2}$ change. Tellus $58,73-87$.

Zhai, X., 2013. On the wind mechanical forcing of the ocean general circulation. J. Geophys. Res. 118, 6561-6577.

Zhai, X., Greatbatch, R. J., 2006a. Inferring eddy-induced diffusivity for heat in the surface mixed layer using satellite data. Geophys. Res. Lett. 33. 
659 Zhai, X., Greatbatch, R. J., 2006b. Surface eddy diffusivity for heat in a 660 model of the northwest Atlantic Osean. Geophys. Res. Lett. 33.

661 Zhai, X., Johnson, H. L., Marshall, D. P., Wunsch, C., 2012. On the wind 662 power input to the ocean general circulation. J. Phys. Oceanogr. 42, 13576631365. 